\title{
Enfoque CTSA em materiais instrucionais produzido por professores de química
}

Luciane Hiromi Akahoshi luhoshi@iq.usp.br

0000-0003-1574-7548

Instituto de Química da

Universidade de São Paulo, São

Paulo, São Paulo

Fabio Luiz Souza

fsouza@iq.usp.br

0000-0001-7597-5038

Instituto de Química da

Universidade de São Paulo, São

Paulo, São Paulo

Maria Eunice Ribeiro Marcondes

mermarco@iq.usp.br

0000-0002-4099-8712

Instituto de Química da

Universidade de São Paulo, São

Paulo, São Paulo

\begin{abstract}
RESUMO
Este trabalho tem como objetivo analisar materiais instrucionais produzidos por professores de química, em uma ação de formação continuada cujo foco foi a contextualização no ensino, numa perspectiva CTSA. Foram analisadas três produções (chamadas unidades didáticas) elaboradas por 12 professores, abordando temáticas relativas a "combustíveis". Os materiais foram analisados segundo cinco perspectivas de contextualização: exemplificação de conceitos com fatos do cotidiano, descrição científica de fatos e processos, problematização da realidade social, compreensão da realidade social e transformação da realidade social. Analisou-se, ainda, o potencial dessas unidades para desenvolver atitudes cidadãs. As três unidades analisadas foram classificadas como descrição científica de fatos e processos, pois enfatizaram principalmente conteúdos científicos. Conhecimentos sobre tecnologia foram os menos abordados, estando ausentes em duas unidades. Apesar disso, percebe-se avanços, pois os materiais apresentaram alguns textos que abordavam aspectos sociais, econômicos e ambientais.
\end{abstract}

PALAVRAS-CHAVE: Formação continuada. Ensino de química. Contextualização e CTSA. 


\section{INTRODUÇÃO}

A contextualização no ensino de Química vem sendo defendida há vários anos. Os argumentos apresentados na defesa da contextualização no ensino consideram a possibilidade de uma integração entre o conhecimento específico e questões problemáticas relacionadas aos temas de interesse dos alunos e da sociedade. Isto traz implicações para o currículo de Química na educação básica, uma vez que o ensino de Química deveria ser planejado tendo em vista a possibilidade de explorar conceitos científicos para que o aluno possa entender e dar sentido ao mundo físico e social, ou seja, para que os conteúdos de química possam ter maior significação para o estudante, além da sala de aula (AIKENHEAD, 1994; ACEVEDODIAZ, 1996).

Uma das vertentes da contextualização, a abordagem CTSA (Ciência, Tecnologia, Sociedade e Ambiente) no ensino de ciências, vem sendo defendida como uma forma de melhorar o senso crítico dos alunos, auxiliando-os a resolver problemas de caráter pessoal e social e possibilitando seu maior envolvimento em questões sobre ciência e tecnologia sob ópticas de cunho político, econômico, social, ambiental etc. (ACEVEDO-DIAZ, 2004; AIKENHEAD, 1994; SANTOS; MORTIMER, 2000; VILCHES; SOLBES; GIL, 2001). Trivelato (1999, p. 204) aponta que, uma vez delegada ao ensino de ciências a responsabilidade de "capacitar os futuros cidadãos a terem uma participação ativa e significativa no processo democrático de tomada de decisão", os professores das disciplinas científicas precisariam ter uma formação que os capacitasse a incluir questões CTS (Ciência, Tecnologia e Sociedade) em seu ensino. Assim, a autora sugere que o professor precisa, ao lado de dominar os conteúdos da disciplina que ensina, saber preparar, selecionar e conduzir atividades que contemplem as relações CTS, assumir a preparação para a cidadania, isto é, preparar os alunos para tomarem decisões sobre temas ou questões relativas às interações entre ciência e sociedade abordados em sala de aula. Portanto, atividades de formação continuada deveriam possibilitar a discussão e reflexão sobre tais necessidades para que os professores possam planejar seu ensino em uma perspectiva CTS.

Tal perspectiva, embora já presente em documentos legais que apresentam propostas para o ensino de Química (PCNEM ${ }^{1}$, Currículo de Química do Estado de São Paulo $^{2}$ ), parece encontrar resistências entre os professores, pois muitos ainda se focam nos conceitos científicos sem proporcionar aos alunos o estabelecimento de relações com aspectos da tecnologia, da sociedade e do ambiente (LIMA, 2016; SILVA; MARCONDES, 2010). Essa resistência pode ser resultante do ensino baseado na aprendizagem memorística de conceitos a que muitos professores são submetidos tanto em sua formação inicial como em suas vivências como estudantes da educação básica.

Nesse cenário, ações de formação continuada podem se constituir em um elemento importante para a reflexão do professor sobre uma perspectiva de ensino que propugna a contextualização dos conhecimentos, abrangendo as relações entre a ciência, a tecnologia, a sociedade e o ambiente. Uma estratégia

\footnotetext{
1 PCNEM: Parâmetros Curriculares Nacionais, área das ciências da natureza, matemática e suas tecnologias, publicação do MEC, 1999. Disponível em http://portal.mec.gov.br/seb/arquivos/pdf/ ciencian.pdf, acesso em 19 de junho de 2017.

${ }^{2}$ Currículo de Química do Estado de São Paulo, publicação da SEESP, 2012. Disponível em

http://www.rededosaber.sp.gov.br/portais/Portals/43/Files/CNST.pdf. Acesso em 19 de junho de 2017.

Página | 125
} 
formativa que auxilia na criação de condições para essas reflexões e para a implementação de um ensino contextualizado é a construção de materiais didáticos pelo próprio professor para suas aulas, uma vez que ele conhece sua realidade escolar, as potencialidades dos alunos e as temáticas de interesse dessa comunidade (SILVA; MARCONDES, 2010; TENREIRO-VIEIRA; VIEIRA, 2005).

Materiais de ensino que apresentem os conteúdos científicos integrados aos contextos social e tecnológico podem facilitar a implementação em sala de aula de abordagens CTS (HOFSTEIN; AIKENHEAD; RIQUARTS, 1988). Entretanto, os livros didáticos de Química, de maneira geral, apresentam a contextualização social apenas com exemplos do cotidiano que ilustram conceitos ou por meio da descrição científica de fatos e processos socialmente relevantes (CUNHA et al., 2012; LAIA; MILLTIZ; COMIOTO, 2016) sem propor níveis mais avançados de contextualização como compreensão ou transformação da realidade social (SILVA; MARCONDES, 2010). Deve-se considerar que o livro didático é bastante utilizado pelos professores de química na seleção e organização do conteúdo a ser ensinado, na escolha de exemplos e de exercícios para suas aulas. Assim, a ausência de um enfoque CTS nesses materiais pode contribuir para que essa perspectiva de ensino não se concretize ou se concretize apenas superficialmente.

Nosso grupo vem oferecendo ações de formação continuada a professores de Química, as quais, partindo das experiências dos professores, apresentam e discutem o ensino com características CTSA e os auxiliam na elaboração de materiais para seu ensino. Em uma ação formativa, desenvolvida com um grupo de professores de Química de escolas de ensino médio da rede pública do Estado de São Paulo, foram construídos, pelos próprios docentes, materiais instrucionais com enfoque CTSA, aqui chamados de unidades didáticas, para serem aplicados em suas aulas.

O objetivo deste trabalho é o de analisar as produções de unidades didáticas com enfoque CTSA desses professores de Química do ensino médio. Procurou-se buscar respostas para as seguintes questões: quais as ideias sobre a contextualização no ensino de química que os professores manifestam e como elas se relacionam com as concepções de contextualização presentes nas unidades didáticas produzidas por eles? Quais aspectos os professores valorizam ao produzir seus materiais didáticos? As unidades produzidas apresentam características que contribuem para o desenvolvimento de senso crítico nos alunos?

\section{FUNDAMENTAÇÃO TEÓRICA}

O ensino de ciências numa perspectiva do movimento CTS objetiva, por meio de articulações entre os conhecimentos da ciência e da tecnologia e o contexto social, desenvolver nos estudantes atitudes e valores cidadãos (AIKENHEAD; RYAN, 1992; AIKENHEAD, 1994; ACEVEDO-DIAZ, 1996; ACEVEDO-DIAZ et al., 2005; AULER, 2003; AULER; DELIZOICOV, 2001; SANTOS; SCHNETZLER, 1997; VILCHES; SOLBES; GIL, 2001).

Três diferentes entendimentos da temática CTS na escola são apontados por Acevedo-Diaz (1996): incrementar a compreensão dos conhecimentos científicos e tecnológicos e suas relações e diferenças para atrair os alunos para esse estudo; potencializar os valores próprios da ciência e tecnologia e sua influência na 
sociedade, procurando aspectos éticos de uso responsável; desenvolver capacidades nos estudantes a fim de que compreendam os impactos sociais da ciência e tecnologia para sua maior participação como cidadão. Segundo o autor, esta última perspectiva proporcionaria ao aluno conhecimentos sobre a ciência mais significativos.

Santos e Mortimer (2000) defendem a elaboração de currículos com ênfase CTS, considerando a influência da ciência e da tecnologia na vida do ser humano moderno. Segundo os autores, a impregnação da ciência e da tecnologia na sociedade provocou um sentimento de fé no progresso devido à ciência, gerando dois mitos: o da salvação da humanidade, acreditando que todos os problemas humanos podem ser resolvidos por meio da ciência; e o da neutralidade, que leva a crer que o conhecimento científico não é influenciado por questões políticas, econômicas, éticas e sociais. Os autores criticam essas ideias apoiados em estudos da filosofia e da sociologia da ciência, que mostram a ineficácia da ciência em solucionar grandes problemas éticos e sócio-políticos da humanidade e a inexistência da neutralidade científica. Os autores propugnam uma alfabetização científica e tecnológica dos cidadãos, não para mostrar maravilhas científicas e tecnológicas, mas para propiciar "ao cidadão agir, tomar decisão e compreender o que está em jogo no discurso dos especialistas" (FOUREZ3 1995 apud SANTOS; MORTIMER, 2000, p. 3).

Assim, o ensino das ciências visa à formação de pessoas conscientes de seus papéis como participantes ativos de tomadas de decisões em assuntos relacionados à ciência e à tecnologia, ou seja, que participem das transformações na sociedade em que vivem, apostando no fortalecimento e ampliação da participação democrática (LINSINGEN, 2007). O autor aponta que a educação em ciências e tecnologia

(...) assume um papel diferente do tradicional, estando muito mais comprometida com uma formação não para a ciência como coisa em si mesma, neutra e independente, mas como uma atividade social, com origem e fim social e por coerência, também política, econômica e culturalmente comprometida e referenciada. Do mesmo modo, também não deverá contemplar a concepção hegemônica de tecnologia, ambientada para a reprodução do sistema dominante, mas para o atendimento de interesses acordados por um número cada vez mais significativo de atores sociais (LINSINGEN, 2007, p. 17).

Aikenhed (1994) propôs um modelo metodológico para o ensino na perspectiva CTS, apontando como o contexto, ao ser adotado como objeto de estudo, deveria produzir questionamentos que envolvessem conhecimentos relacionados às três áreas (figura 1 ) - Ciência, Tecnologia e Sociedade.

\footnotetext{
${ }^{3}$ FOUREZ, Gerard. A construção das ciências: introdução à filosofia e à ética das ciências. São Paulo: Editora da Universidade Estadual
} Paulista, 1995.

Página | 127 
Figura 1 - Modelo metodológico CTS proposto por Aikenhead (1994, tradução nossa).

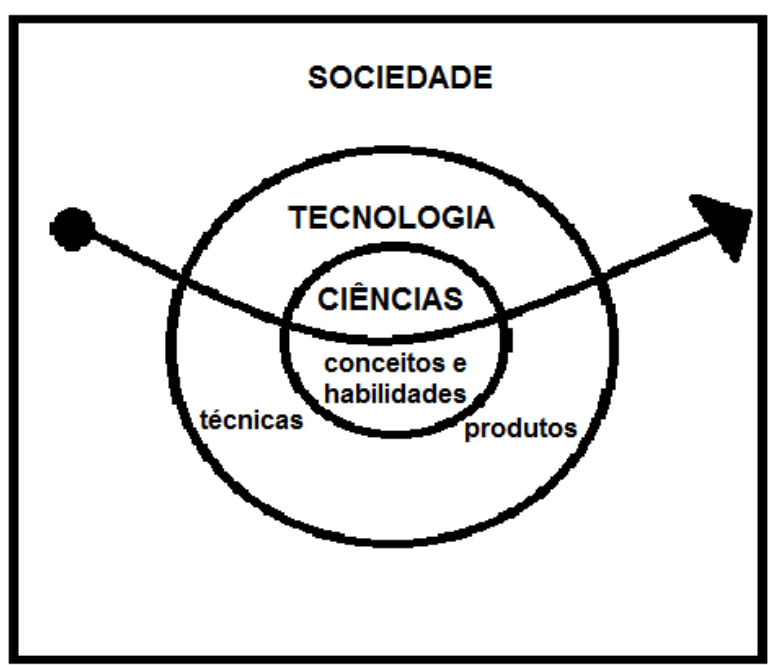

(Fonte: Traduzido de Aikenhead)

Nesse modelo, um problema ou objeto de estudo inicia-se por uma questão de interesse social relacionada a conhecimentos científicos e tecnológicos. Nesse enfoque, os conteúdos de ciências são apresentados para entender o tema e a tecnologia envolvida, retomando-se os aspectos tecnológicos e sociais, com o apoio dos conhecimentos científicos. Dessa maneira, o autor indica que o aprendiz poderia ser capaz de apontar soluções e tomar decisões sobre a questão social tratada. Nesse tipo de abordagem, a contextualização deixa de ser uma mera exemplificação do cotidiano e torna-se o princípio que norteará o estudo.

Referendando essa abordagem, Acevedo-Diaz (1996) argumenta que o ensino deve estar focado em problemas sócio-científicos para que os alunos busquem soluções e, assim, aprendam a argumentar, defender pontos de vista, formular questões. Ainda, tal modelo possibilitaria ao estudante a integração de seu conhecimento pessoal do mundo natural, ou seja, seu conhecimento científico com conhecimentos da tecnologia e de seu mundo social (HOFSTEIN; AIKENHEAD; RIQUARTS, 1988).

Implementar uma perspectiva CTS em sala de aula requer professores que, diferentemente do modelo tradicional de ensino, tenham formação para: incluir questões e temas sociais, relacionando-os a conhecimentos científicos, promover um ambiente de interação entre os alunos e de questionamentos sobre o alcance e a limitação da ciência e da tecnologia na solução de problemas da sociedade atual (ACEVEDO-DIAZ, 1996). Esses saberes, ainda incipientes na formação inicial do professor, podem ser problematizados em atividades de formação continuada planejadas para que o professor possa refletir sobre sua prática docente e possa, como aponta Sacristán (2008, p. 75), "intervir em todos os domínios que influenciam a prática docente, no sentido de sua emancipação e desenvolvimento profissional".

Alguns trabalhos têm mostrado que os professores concordam com a ideia de contextualizar socialmente o ensino de ciências, mas, na prática, resistem a fazer mudanças nos conteúdos que abordam em sala de aula (VILCHES; SOLBES; GIL, 
2001; SILVA; MARCONDES, 2010). Essa resistência dos professores pode estar relacionada, além dos aspectos destacados anteriormente quanto a sua formação, à pequena disponibilidade de materiais instrucionais que o auxiliem na adoção de um ensino contextualizado em níveis mais avançados. Assim, a abordagem com enfoque CTS é entendida como uma introdução de exemplos do dia a dia dos estudantes que ilustram os conteúdos tradicionalmente ensinados. Para superar essa visão restrita, atividades de formação continuada voltadas para ampliar abordagens CTSA no ensino deveriam focar a problematização das ideias de contextualização apresentadas pelos professores, sistematizando os conhecimentos teóricos e práticos pertinentes a essas ideias e contribuir para aplicação de concepções mais elaboradas de contextualização no ensino (SILVA, 2007).

Desse ponto de vista, a elaboração por parte dos professores de seus próprios materiais de ensino tem se mostrado uma estratégia eficaz na formação continuada de professores, pois essa atividade pode aproximar o discurso do professor a sua prática cotidiana (MAZZEU, 1998). Tenreiro-Vieira e Vieira (2005) apontam que a construção e a validação de materiais didáticos de perspectiva CTS devam ser realizadas em conjunto entre pesquisadores e professores, em atividades de formação continuada de professores de Ciências.

Santos (2001, p. 141) apresenta um conjunto de critérios a serem contemplados por materiais didáticos que adotam uma abordagem CTS:

$\checkmark \quad$ Responsabilidade: “O material desenvolve a compreensão dos alunos relativamente à sua interdependência como membros da sociedade e da sociedade como agente responsável dentro do ecossistema da natureza".

$\checkmark \quad$ Influências mútuas CTS: o material apresenta claramente as relações mútuas entre a tecnologia, a ciência e a sociedade.

$\checkmark$ Relação com as questões sociais: "As relações dos desenvolvimentos tecnológicos e científicos com a sociedade são claramente estabelecidas, no sentido de uma atenção dirigida".

$\checkmark$ Balanço de pontos de vista: "O material apresenta um balanço de diferentes pontos de vista sobre questões e opções, sem necessariamente se esforçar por esconder a perspectiva do autor".

$\checkmark \quad$ Tomada de decisões e resolução de problemas: O material encoraja os alunos à procura de soluções para problemas e para tomada de decisão.

$\checkmark$ Ação responsável: "O material encoraja os alunos para que se envolvam em ações sociais ou pessoais, depois de ponderarem as consequências de valores e efeitos projetados por vários cenários e opções alternativas".

$\checkmark \quad$ Integração de um ponto de vista: O material ajuda os alunos a irem além do assunto específico, até considerações mais alargadas de ciência, tecnologia e sociedade que incluam um tratamento de valores/éticas pessoais e sociais.

Esses critérios foram utilizados por Freitas e Santos (2004) e se mostraram adequados para analisar materiais didáticos produzidos por um grupo de professores universitários, estudantes de graduação e professores de ensino

${ }^{4}$ Os termos entre aspas foram apresentados como no texto original e os que não se encontram dessa forma foram paráfrases desse texto Página | 129 
médio, de Biologia, como parte de um projeto de desenvolvimento de materiais para o ensino de ciências, em que se buscava a incorporação da ciência e tecnologia no trabalho pedagógico.

Considerando o modelo metodológico apresentado por Aikenhead (1994), figura 1, Marcondes et al. (2007) propõem um modelo estrutural para a construção de materiais instrucionais de ensino contextualizado, apresentado na figura 2.

Figura 2 - Modelo estrutural de uma unidade didática contextualizada (MARCONDES et al., 2007, p. 21).

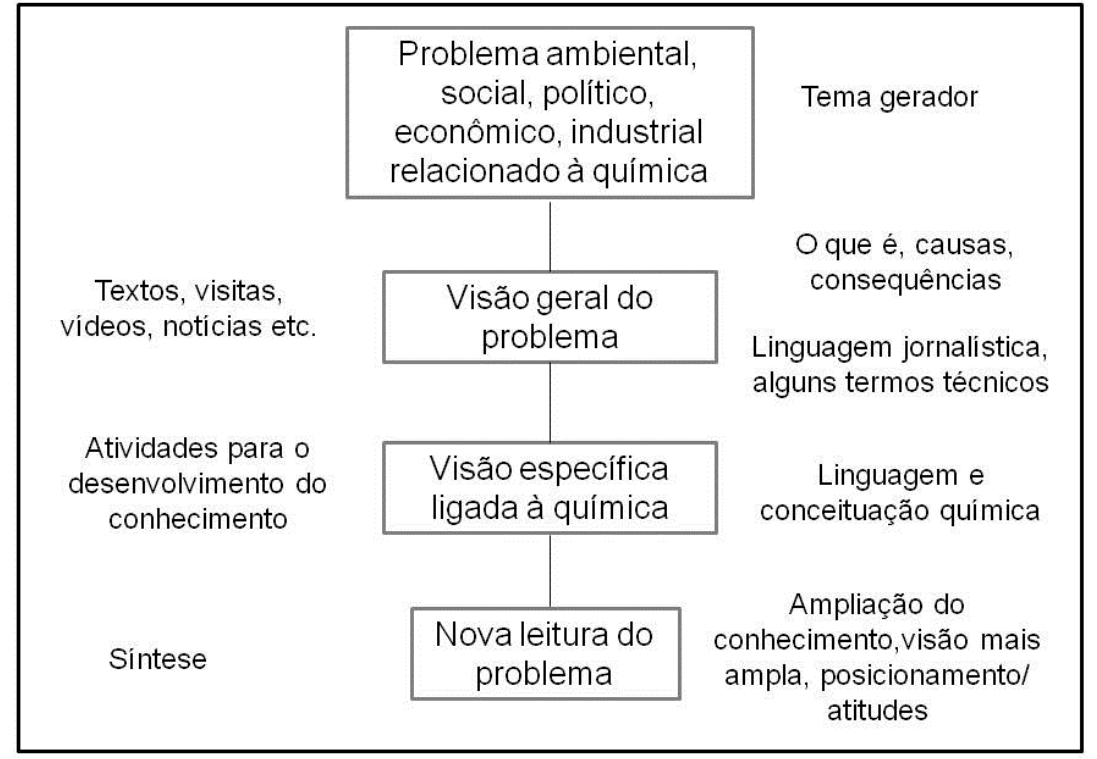

(Fonte: Marcondes et al.)

Nessa abordagem, o professor escolhe um problema que considere interessar aos alunos, que apresente relações com conhecimentos químicos; seriam dados subsídios ao estudante para que compreendesse o problema de forma geral, como dados, interpretações, diferentes visões; seriam, também, dados subsídios para entendimentos na perspectiva científica, de maneira que o aluno pudesse fazer uma nova leitura do problema, baseando-se nos conhecimentos tratados e em seus próprios, e em suas concepções.

Em uma ação de formação continuada, o professor, ao se engajar em um processo contínuo de reflexões sobre sua prática e de compartilhamento de conhecimentos e experiências, e procurar elaborar um material com essa perspectiva, pode rever seus conceitos sobre o ensino e a contextualização dos conhecimentos científicos.

Iniciativas de formação continuada baseadas na produção de material didático como estratégia para formação de professores já foram descritas. Eichler e Del Pino (2010) relatam uma experiência de formação em serviço em que foram confeccionados materiais didáticos sobre diversas temáticas, tais como, poluição do ar, siderurgia, agrotóxicos e ambiente, saúde e medicamentos, entre outros. Os autores também consideram que a produção de material didático é importante para a qualificação profissional do professor e que pode resultar na melhoria da qualidade de seu trabalho e consequentemente na formação de seus alunos. Além 
disso, eles entendem "a necessidade de enfocar essa formação como uma forma de política cultural, que defina os professores como intelectuais responsáveis pela criação de espaço público de educação para a cidadania" e também a necessidade de "desenvolver e manter políticas públicas que articulem a formação de professores e a constituição de espaços possíveis para que ocorra a prática reflexiva, sendo um desses espaços a produção de material didático" (EICHLER; DEL PINO, 2010, p. 652-653).

Bernardo, Vianna e Fontoura (2007) apresentam um estudo relacionado a um projeto de formação continuada de professores de física estruturado a partir do tema "produção e consumo de energia elétrica nas salas de aula do ensino médio". O curso proposto envolveu dois momentos: um com aulas expositivas sobre as relações entre energia, desenvolvimento e ambiente e sobre a abordagem baseada no enfoque CTSA; e outro com oficinas nas quais os professores puderam discutir e elaborar estratégias consideradas pelo grupo como adequadas para desenvolver o tema, levando em conta os aspectos científicos, tecnológicos, políticos, econômicos, sociais e ambientais de acordo com o enfoque CTSA. Os autores apontam que foi identificado um grupo de professores com concepções e práticas tradicionais, com pouco conhecimento sobre o enfoque CTSA, mas que houve uma evolução do grupo em relação à conscientização da importância do tema e da abordagem com enfoque CTSA, porém há uma visão limitada quanto aos aspectos multidisciplinares do enfoque CTSA. Como conclusão, os autores acreditam em poder transformar a atitude dos professores ao valorizar sua voz e propiciar momentos de diálogo entre seus pares para refletirem sobre suas práticas e construírem seus próprios caminhos pedagógicos.

\section{MÉTODOS}

Os materiais instrucionais (chamados de unidades didáticas) foram produzidos em um curso de formação continuada de professores de química, cujo objetivo era que o professor refletisse sobre aspectos pedagógicos teóricos e práticos para o ensino de química, principalmente a importância da contextualização do conhecimento científico e da experimentação de caráter investigativo. Nesse sentido, procurou-se o desenvolvimento de competências ligadas à autonomia docente em relação à pesquisa, seleção e produção de materiais didáticos. Além desses aspectos, as unidades deveriam considerar as especificidades da prática pedagógica do docente, seus interesses e de seus alunos.

O curso contou com 99 professores da rede pública de ensino, abrangendo diversas regiões e diretorias de ensino do estado de São Paulo; teve duração de 64 horas, sendo realizados encontros quinzenais ou mensais, aos sábados, na universidade, ao longo de 7 meses. Os encontros tiveram início no segundo semestre de 2009, houve um recesso entre os meses de dezembro e fevereiro, retomando-se em fevereiro de2010. Por sugestão da Secretaria de Educação do Estado de São Paulo, os participantes eram professores efetivos da rede pública de ensino.

O curso se estruturou da seguinte maneira: nos dois primeiros encontros foram discutidas as visões e práticas dos participantes sobre a temática e apresentados subsídios relativos a diferentes enfoques para o ensino CTS; no 
primeiro encontro procurou-se conhecer as ideias iniciais dos professores sobre o ensino contextualizado por meio de um questionário de resposta livre; no segundo encontro, os professores propuseram temas que gostariam de abordar em suas aulas e organizaram-se os grupos de elaboração em função de interesses comuns; o terceiro encontro foi reservado para a discussão das características que as unidades deveriam apresentar, tendo sido discutidos os modelos metodológicos de Aikenhead (1994, vide figura 1) e de Marcondes (2008, vide figura 2), e os grupos foram convidados a tomar suas decisões a respeito da organização da unidade didática (conteúdos, duração, tipo de atividade, público alvo, situação problema), nesse encontro, os professores apresentaram uma primeira estrutura da unidade, utilizando o esquema proposto (figura 2); do quarto ao sexto encontro, os professores se dedicaram à produção e discussão coletivas de suas unidades, as quais foram apresentadas no sétimo e último encontro. Durante os encontros de planejamento e de elaboração das unidades (encontros 2 a 6), cada grupo contou com um mediador de nosso grupo, que subsidiava os professores com materiais, discussões e informações solicitadas. As unidades deveriam conter todos os materiais que seriam utilizados com os alunos, como textos, experimentos, exercícios, jogos, simulações etc., bem como os professores deveriam apontar os objetivos gerais de sua unidade e de cada aula, os conteúdos a serem tratados, explicitando a natureza desses conteúdos (C, T, S, A). Os encontros de 4 a 6 ocorreram com um intervalo quinzenal entre cada um, nesses, os professores trabalhavam na elaboração da unidade, faziam pesquisa bibliográficas, testavam experimentos, elaboravam ou adaptavam textos, formulavam questões, apresentando e discutindo suas produções com os demais colegas e com nosso grupo, dando-se subsídios para a continuidade da elaboração. $O$ encontro final ocorreu três meses após o sexto, de maneira que os professores tivessem um tempo maior para a produção completa da unidade. Nesse período, eventuais consultas ao nosso grupo foram feitas virtualmente ou pessoalmente, dependendo da disponibilidade do professor. A partir da formação dos grupos, os professores que compunham cada grupo trabalharam conjuntamente na construção da unidade, as decisões eram tomadas de maneira consensual, as sugestões de atividades eram discutidas no grupo, havendo a mediação de um membro de nosso grupo.

As análises das unidades didáticas produzidas foram feitas considerando-se os seguintes aspectos: entendimento de contextualização dos professores manifestado nas unidades produzidas; os conteúdos referentes à ciência, à tecnologia, à sociedade e ao ambiente presentes nas unidades e as inter-relações dos conteúdos explícitas nessas unidades. A partir da análise desses elementos, procurou-se caracterizar a perspectiva de contextualização dominante do material. Foram foco de análise unidades produzidas sobre o tema energia.

Para analisar como se manifesta a contextualização no material produzido utilizaram-se as categorias adaptadas de Silva (2007) sobre diferentes perspectivas de contextualização discutidas na literatura. $O$ quadro 1 apresenta as perspectivas de contextualização utilizadas para análise. 
Quadro 1 - Perspectivas de contextualização utilizadas na análise das unidades didáticas produzidas pelos professores.

\begin{tabular}{|c|l|c|}
\hline $\begin{array}{c}\text { Perspectiva de } \\
\text { contextualização }\end{array}$ & \multicolumn{1}{c|}{ Descrição } \\
\hline $\begin{array}{c}\text { Exemplificação do } \\
\text { conhecimento }\end{array}$ & $\begin{array}{l}\text { Apresentação de ilustrações e exemplos de fatos do cotidiano e } \\
\text { de aspectos tecnológicos relacionados ao conteúdo que está } \\
\text { sendo tratado. }\end{array}$ \\
\hline $\begin{array}{c}\text { Descrição científica } \\
\text { de fatos e } \\
\text { processos }\end{array}$ & $\begin{array}{l}\text { Ponte entre os conteúdos da química e questões do cotidiano, } \\
\text { inclusão de temáticas tecnológicas e sociais. }\end{array}$ \\
\hline $\begin{array}{c}\text { Problematização da } \\
\text { realidade social }\end{array}$ & $\begin{array}{l}\text { Discussão de situações problemáticas de caráter social, } \\
\text { tecnológico e ambiental, com pouca ênfase no conhecimento } \\
\text { científico. Os conteúdos específicos surgem em função da } \\
\text { situação em estudo e são tratados de forma superficial. }\end{array}$ \\
\hline $\begin{array}{c}\text { Compreensão da } \\
\text { realidade social }\end{array}$ & $\begin{array}{l}\text { Interligação entre o conhecimento científico, social, tecnológico } \\
\text { e ambiental, para o posicionamento frente às situações } \\
\text { problemáticas. Possibilidade de desenvolvimento de } \\
\text { competências de análise e julgamento. Os conteúdos específicos } \\
\text { surgem em função da situação em estudo e são tratados de } \\
\text { forma aprofundada. }\end{array}$ \\
\hline $\begin{array}{c}\text { Transformação da } \\
\text { realidade social }\end{array}$ & $\begin{array}{l}\text { Discussão de situações problemas de forte teor social, buscando } \\
\text { sempre, o posicionamento e intervenção social por parte do } \\
\text { aluno na realidade social problematizada. Assim, os conteúdos } \\
\text { são definidos em função da problemática em estudo e das } \\
\text { necessidades que se apresentam. Neste caso, devem aparecer } \\
\text { atividades que promovam o estudo sistematizado visando } \\
\text { possíveis açães para transformação da realidade social estudada. }\end{array}$ \\
\hline
\end{tabular}

(Fonte: Adaptado de Silva, 2007)

Os conteúdos abordados nas unidades didáticas foram classificados em quatro blocos: ciência, tecnologia, sociedade e ambiente, após a leitura da unidade didática. Duas classificações independentes foram feitas e compararam-se as diferenças, a fim de se proceder a uma validação. Os professores autores das unidades foram convidados a apresentar uma classificação própria dos conteúdos tratados nesses quatro blocos, para que pudessem ter uma visão dos conhecimentos que estavam tratando e de possíveis ênfases que estavam dando às suas unidades. As classificações apresentadas pelos próprios autores das unidades foram comparadas com a elaborada por nós. Foi sugerido aos professores que utilizassem o esquema apresentado na figura 3, para indicar, no centro do retângulo, o tema ou situação-problema escolhido e ao redor os conteúdos de ciência (C), tecnologia $(T)$, sociedade $(S)$ e ambiente $(A)$ relacionados ao tema presentes na unidade. Embora esse esquema não indique as possíveis interações entre os quatro componentes, ele se mostrou uma ferramenta útil na explicitação dos conteúdos relacionados ao tema escolhido para a unidade elaborada pelos professores em cada uma das vertentes CTSA. Esse esquema pode revelar ao elaborador os focos principais de sua unidade, assim como as lacunas de conhecimentos que o tema da unidade exigiria. Assim, o esquema tem se mostrado útil na elaboração de planos de aula. Um esquema de mesma natureza foi também elaborado pelos pesquisadores após a leitura do material produzido pelos grupos de professores. 
Figura 3 - Esquema para relacionar conteúdos CTSA a um tema.

$\mathrm{C}$

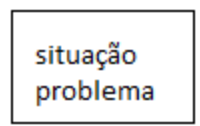

$\mathrm{T}$

A

(Fonte: Elaboração dos autores.)

Para analisar as inter-relações entre os conteúdos e os aspectos de contextualização do material, as seguintes categorias foram estabelecidas (MARCONDES et al., 2009; AKAHOSHI, 2012):

i) Problematização: verificou-se a presença ou não de uma problematização de caráter social ou situação problema ou tema, relacionada a conhecimentos químicos, que se caracteriza por situações que solicitam ao aluno expor o que pensa, interpretá-las, assim como avaliar soluções e propostas de intervenção. Além disso, procurou-se verificar se o tema se desenvolvia ao longo do material ou era apenas inicial. 0 quadro 2 apresenta o modelo do instrumento de análise utilizado para classificar as unidades didáticas para esse item.

Quadro 2-Modelo do instrumento para classificar a problematização nas unidades didáticas.

\begin{tabular}{|l|c|c|c|}
\hline \multirow{2}{*}{ Unidade } & \multicolumn{3}{|c|}{ Problematização } \\
\cline { 2 - 4 } & Apenas Inicial & Ao longo & Ausente \\
\hline & & & \\
\hline
\end{tabular}

ii) Experimentos propostos: verificou-se a relação dos experimentos com o tema de estudo, utilizando-se níveis de relação: 0 - quando o experimento não abordava conceitos que pudessem promover o entendimento de algum aspecto do tema; 1 - quando essa relação era fraca ou se apresentava de maneira indireta com o tema; 2 - quando o experimento tratava de conceitos envolvidos na resolução do problema em estudo ou promovesse o entendimento de alguns aspectos vinculados ao tema. Além disso, analisou-se a natureza do experimento, criando-se as seguintes categorias: científico - quando os experimentos exploram o conceito em si mesmo; e cotidiano ou CTSA - quando os experimentos exploram o conceito no contexto do tema. As questões apresentadas após a realização da atividade experimental também foram classificadas procurando verificar se promoviam: entendimento do trabalho realizado, aplicação do conceito desenvolvido, interpretação de outros conceitos ou problemas que não estão sendo desenvolvidos no experimento; julgamento por parte dos alunos da questão problema ou de algum aspecto relacionado a ele, possibilidade de resolução do problema ou de algum aspecto relacionado a ele. 0 quadro 3 apresenta o modelo do instrumento de análise utilizado para classificar as unidades didáticas para esse item. 
Quadro 3 - Modelo do instrumento para analisar os experimentos propostos nas unidades didáticas.

\begin{tabular}{|c|c|c|c|c|c|c|c|c|}
\hline \multicolumn{9}{|c|}{ Experimentos } \\
\hline \multirow{2}{*}{$\begin{array}{c}\text { Experi- } \\
\text { mento }\end{array}$} & \multicolumn{2}{|c|}{ Natureza } & $\begin{array}{c}\text { Relação com } \\
\text { o tema }\end{array}$ & \multicolumn{5}{|c|}{ Questões } \\
\cline { 2 - 9 } & Científico & $\begin{array}{c}\text { Cotidiano } \\
\text { ou CTSA }\end{array}$ & 0 a 2 & $\begin{array}{c}\text { Entendi- } \\
\text { mento }\end{array}$ & $\begin{array}{c}\text { Aplica- } \\
\text { ção }\end{array}$ & $\begin{array}{c}\text { Interpre- } \\
\text { tação }\end{array}$ & $\begin{array}{c}\text { Julga- } \\
\text { mento }\end{array}$ & $\begin{array}{c}\text { Reso- } \\
\text { lução }\end{array}$ \\
\hline & & & & & & & & \\
\hline
\end{tabular}

iii) Textos: verificou-se o nível de relação com o tema proposto, seguindo os mesmos níveis de relação ( 0 a 2 ) utilizados para os experimentos. Os textos foram classificados, também, se poderiam ser problematizadores, ou seja, se solicitam ao aluno expor o que pensa ou sua interpretação ou mesmo como avaliar soluções e propostas de intervenção, independentes de estarem relacionados diretamente ao tema da unidade. A natureza da informação existente no texto também foi analisada, verificando-se as ênfases dadas aos conteúdos relacionados à Ciência (C), à Tecnologia ( $T$ ), à Sociedade (S) e ao Ambiente (A). As questões apresentadas após o texto foram classificadas procurando verificar se promoviam: entendimento do assunto tratado, aplicação de conceito ou conteúdo abordado, tomada de decisões por parte do aluno da questão problema ou de algum aspecto relacionado a ela, julgamento por parte dos alunos da questão problema ou de algum aspecto relacionado a ela, possibilidade de resoluções do problema ou de algum aspecto relacionado a ela. $\mathrm{O}$ quadro 4 apresenta o modelo do instrumento de análise utilizado para classificar as unidades didáticas para esse item.

Quadro 4 - Modelo do instrumento para analisar os textos apresentados nas unidades didáticas.

\begin{tabular}{|c|c|c|c|c|c|c|c|c|c|c|c|c|}
\hline \multirow{2}{*}{ Texto } & \multicolumn{4}{|c|}{$\begin{array}{l}\text { Natureza da } \\
\text { Informação }\end{array}$} & \multicolumn{2}{|c|}{$\begin{array}{c}\text { Problema- } \\
\text { tização }\end{array}$} & \multirow{2}{*}{\begin{tabular}{|c|}
$\begin{array}{c}\text { Relação com } \\
\text { o tema }\end{array}$ \\
0 a 2
\end{tabular}} & \multicolumn{5}{|c|}{ Questões } \\
\hline & C & $\mathrm{T}$ & $S$ & A & Sim & Não & & $\begin{array}{l}\text { Entendi- } \\
\text { mento }\end{array}$ & $\begin{array}{l}\text { Apli- } \\
\text { cação }\end{array}$ & $\begin{array}{c}\text { Interpre- } \\
\text { tação }\end{array}$ & $\begin{array}{l}\text { Julga- } \\
\text { mento }\end{array}$ & $\begin{array}{l}\text { Reso- } \\
\text { lução }\end{array}$ \\
\hline & & & & & & & & & & & & \\
\hline
\end{tabular}

iv) Atividades: verificou-se se a unidade didática sugeria outras atividades para o desenvolvimento do tema, qual o nível de relação com o tema proposto, as ênfases dadas aos conteúdos relacionados à Ciência (C), à Tecnologia (T), à Sociedade (S) e ao Ambiente (A) e se apresentava questões. As atividades foram classificadas, também, como problematizadoras, se solicitassem ao aluno expor o que pensa ou sua interpretação ou avaliação de soluções ou proposição de intervenção, independentes de estarem relacionadas diretamente ao tema da unidade. As questões apresentadas após a atividade também foram classificadas, utilizando-se os mesmos critérios apresentados para análise das questões dos experimentos. $\mathrm{O}$ quadro 5 apresenta o modelo do instrumento de análise utilizado para classificar as unidades didáticas para esse item. 
Quadro 5 - Modelo do instrumento para analisar outras atividades propostas nas unidades didáticas.

\begin{tabular}{|c|c|c|c|c|c|c|c|c|c|c|}
\hline \multicolumn{11}{|c|}{ Outras Atividades: (debates, jogos, pesquisas etc.) } \\
\hline \multirow{2}{*}{$\begin{array}{l}\text { Tipo de } \\
\text { atividade }\end{array}$} & \multirow{2}{*}{$\begin{array}{c}\text { Relação } \\
\text { com o } \\
\text { tema }\end{array}$} & \multicolumn{4}{|c|}{ Conteúdos } & \multicolumn{5}{|c|}{ Questões } \\
\hline & & C & $\mathrm{T}$ & $\mathrm{S}$ & A & $\begin{array}{l}\text { Entendi- } \\
\text { mento }\end{array}$ & $\begin{array}{l}\text { Aplica- } \\
\text { ção }\end{array}$ & $\begin{array}{l}\text { Interpre- } \\
\text { tação }\end{array}$ & $\begin{array}{l}\text { Julga- } \\
\text { mento }\end{array}$ & $\begin{array}{l}\text { Reso- } \\
\text { lução }\end{array}$ \\
\hline & & & & & & & & & & \\
\hline
\end{tabular}

Ainda, as unidades foram analisadas quanto às características que materiais curriculares de orientação CTSA deveriam apresentar, propostas por Santos (2001). Para essa análise, procedeu-se à leitura da unidade, guiada por algumas questões orientadoras (Santos, 2001, p. 180), procurando evidenciar nos textos, questões e outras atividades propostas a presença de indicadores dessas características. Assim, a análise foi guiada por questões como: o material ilustra o papel da ciência e da tecnologia na sociedade e proporciona ao aluno o conhecimento de diferentes cenários relativos ao problema?; coloca o aluno em contato com situações reais e encoraja-os a buscar soluções?; apresenta ou direciona o aluno a buscar informações científicas, técnicas ou sociais pertinentes ao problema em estudo?; entre outras apresentadas por Santos (2001).

\section{RESULTADOS E ANÁLISE}

As unidades didáticas foram elaboradas tendo como base o modelo de material contextualizado proposto por Marcondes et al. (2007, p. 21). Vinte e quatro unidades didáticas foram produzidas, tendo sido agrupadas em quatro focos temáticos: combustíveis - produção, eficiência e problemas ambientais ( 7 unidades); Metais - produção, usos e impactos ambientais (4 unidades); Água: usos e tratamento ( 2 unidades); Questões ambientais em diferentes contextosreflexões e soluções (8 unidades, temas distintos, tais como: lixo, solo, derramamento de petróleo); outras unidades tratavam de diversos temas. Neste trabalho foram analisadas as unidades cujos temas se relacionavam a "combustíveis", em que foram tratados aspectos da produção, da eficiência e impactos ambientais. O tema em questão foi escolhido por sete grupos, tendo sido produzidas cinco unidades completas e duas incompletas, estas últimas constando apenas alguns planos de aula. Foram analisadas neste trabalho três das unidades completas, pois duas unidades não foram incluídas por apresentarem similaridades às demais analisadas. O tema combustível foi escolhido pelo fato de agrupar o maior número de unidades com conteúdos próximos e ter envolvido cerca de $30 \%$ dos professores participantes. As unidades analisadas, bem como o número de professores envolvidos constam do Quadro $6^{5}$.

Quadro 6 - Unidades produzidas pelos professores que foram analisadas.

\begin{tabular}{|c|c|c|}
\hline Tema & Nome da unidade & $\begin{array}{c}\text { № de } \\
\text { professores }\end{array}$ \\
\hline & Combustíveis & 3 \\
\hline
\end{tabular}

5 As demais unidades tiveram os seguintes títulos: “Há vantagem no carro flex" (4 professores), "Biodiesel” (3 professores), "Emissão de gases por motores a explosão" (5 professores), "Vantagens e desvantagens do álcool como combustível” (4 professores).

Página | 136 


\begin{tabular}{|c|c|c|}
\hline \multirow{2}{*}{$\begin{array}{c}\text { Combustíveis - Produção, } \\
\text { eficiência e impactos ambientais }\end{array}$} & Energia e combustão & 4 \\
\cline { 2 - 3 } & $\begin{array}{c}\text { Relação custo benefício entre etanol e } \\
\text { gasolina }\end{array}$ & 5 \\
\hline
\end{tabular}

Cada uma dessas unidades didáticas foi caracterizada em uma perspectiva de contextualização (MARCONDES et al., 2009; SILVA; MARCONDES, 2010) a partir das análises dos elementos pedagógicos apresentados no material elaborado (textos, experimentos, exercícios etc.), conforme apresentado no quadro 7.

Exemplificação: a contextualização é abordada apenas por exemplos do dia a dia, o ensino não enfatiza uma problematização para desenvolver o conteúdo e sim uma abordagem em que prevalece o enfoque de conteúdos científicos. Não há um tratamento mais aprofundado de algum tema relativo aos exemplos dados. Também, tendo como base o enfoque tradicional, considerou-se que os experimentos propostos não têm a finalidade de explorar a contextualização. As atividades, questões e textos apresentados na unidade estão mais voltados aos conhecimentos específicos de Química, pouco explorando os exemplos dados.

Descrição científica de fatos e processos: são incluídas no ensino descrições científicas de processos de interesse social, tecnológico ou ambiental; de modo geral, os conteúdos científicos seguem a sequência tradicional, sendo apresentados temas considerados socialmente relevantes estreitamente ligados a tais conteúdos. A unidade didática construída com esse foco não tem como eixo principal a problematização, podendo apresentar, inicialmente, uma situação relativa à sociedade que justificará a introdução dos conteúdos e do tema abordado. Os experimentos propostos são focados nos conteúdos químicos, bem como as demais atividades.

Problematização da realidade social: todos os conteúdos passam a ser desenvolvidos em função do problema apresentado. Considerou-se que uma unidade didática elaborada nessa perspectiva apresenta uma problematização em toda a sequência de ensino e os conteúdos de natureza social são tratados com mais ênfase do que os científicos. A experimentação e as atividades propostas têm a finalidade de explorar o problema em estudo.

Compreensão da realidade social: o foco do ensino é possibilitar o posicionamento do aluno frente a situações sócio-científicas problemáticas, os conteúdos são desenvolvidos em função do tema tratado. A problematização, nesse tipo de abordagem, deve se desenvolver ao longo da unidade didática, os conteúdos científicos e os de caráter social, tecnológico ou ambiental apresentarão relação estreita e um não prevalece sobre os outros, uma vez que o aluno deve ter uma visão ampla para poder fazer seus julgamentos. Os experimentos e as demais atividades estão relacionados à problemática tratada, pois fornecem subsídios para a compreensão e análise da situação.

Transformação da realidade social: os conteúdos químicos são desenvolvidos em função de um problema social apresentado, mas de caráter local, ou seja, que afeta a comunidade na qual o aluno está inserido. A problematização nessa perspectiva está presente em toda a sequência de ensino; as atividades e os experimentos têm a finalidade de explorar o tema; e os conteúdos de natureza social são tratados com mais ênfase que os científicos. A diferença com a abordagem relativa à problematização encontra-se no desenvolvimento de 
atitudes em relação ao problema, neste caso há uma ênfase em desencadear mobilizações e ações individuais e coletivas por parte dos estudantes para atuar junto à comunidade a fim de procurar soluções para o problema abordado.

Quadro 7 - Perspectivas de contextualização e aspectos pedagógicos.

\begin{tabular}{|c|c|c|c|c|c|c|}
\hline $\begin{array}{l}\text { Entendimen } \\
\text { to de } \\
\text { contex- } \\
\text { tualização }\end{array}$ & $\begin{array}{l}\text { Proble- } \\
\text { matiza- } \\
\text { ção }\end{array}$ & $\begin{array}{l}\text { Enfoque } \\
\text { CTSA na } \\
\text { visão geral } \\
\text { do tema }\end{array}$ & \begin{tabular}{|} 
Conhecimen- \\
to específico \\
de química em \\
relação ao \\
tema
\end{tabular} & \begin{tabular}{|c|} 
Experimen- \\
tação (rela- \\
ção com o \\
tema, \\
natureza)
\end{tabular} & $\begin{array}{l}\text { Caracte- } \\
\text { rísticas das } \\
\text { atividades }\end{array}$ & $\begin{array}{c}\text { Nova visão } \\
\text { do tema }\end{array}$ \\
\hline $\begin{array}{l}\text { Exemplifica- } \\
\text { ção do co- } \\
\text { nhecimento }\end{array}$ & Ausente & $C>T S A$ & relação fraca & $\begin{array}{l}\text { sem relação, } \\
\text { científico }\end{array}$ & $\begin{array}{l}\text { não pro- } \\
\text { blemati- } \\
\text { zadoras }\end{array}$ & $\begin{array}{c}\text { não } \\
\text { apresenta }\end{array}$ \\
\hline $\begin{array}{c}\text { Descrição } \\
\text { científica de } \\
\text { fatos e } \\
\text { processos }\end{array}$ & Inicial & $C>T S A$ & relação média & $\begin{array}{c}\text { relação } \\
\text { fraca, } \\
\text { científico }\end{array}$ & $\begin{array}{l}\text { não pro- } \\
\text { blemati- } \\
\text { zadoras }\end{array}$ & $\begin{array}{l}\text { retoma o } \\
\text { tema }\end{array}$ \\
\hline $\begin{array}{c}\text { Problemati- } \\
\text { zação da } \\
\text { realidade } \\
\text { social }\end{array}$ & Contínua & $\mathrm{CT}<\mathrm{SA}$ & relação forte & $\begin{array}{c}\text { relação dire- } \\
\text { ta, cotidiano } \\
\text { ou CTSA }\end{array}$ & $\begin{array}{l}\text { problema- } \\
\text { tizadoras }\end{array}$ & $\begin{array}{c}\text { amplia o } \\
\text { entendi- } \\
\text { mento }\end{array}$ \\
\hline $\begin{array}{l}\text { Compreen- } \\
\text { são da reali- } \\
\text { dade social }\end{array}$ & Contínua & $\mathrm{C}=\mathrm{TSA}$ & relação forte & $\begin{array}{c}\text { relação dire- } \\
\text { ta, cotidiano } \\
\text { ou CTSA }\end{array}$ & $\begin{array}{l}\text { problema- } \\
\text { tizadoras }\end{array}$ & $\begin{array}{c}\text { busca } \\
\text { resolver o } \\
\text { problema }\end{array}$ \\
\hline $\begin{array}{l}\text { Transforma- } \\
\text { ção da reali- } \\
\text { dade social }\end{array}$ & Contínua & $\mathrm{CTA}<\mathrm{S}$ & relação forte & $\begin{array}{c}\text { relação dire- } \\
\text { ta, cotidiano } \\
\text { ou CTSA }\end{array}$ & $\begin{array}{l}\text { problema- } \\
\text { tizadoras }\end{array}$ & $\begin{array}{c}\text { busca re- } \\
\text { solver o } \\
\text { problema, } \\
\text { motivan- } \\
\text { do ações } \\
\text { pessoais } \\
\text { ou } \\
\text { coletivas }\end{array}$ \\
\hline
\end{tabular}

Foram feitas leituras de cada unidade, identificando-se os conteúdos e as atividades propostas e foram analisados cada um dos elementos pedagógicos, construindo-se uma visão ampla da unidade. A seguir, apresentam-se os resultados das análises de cada uma das unidades, não exibindo, por questões de espaço, as classificações de cada elemento. Essas análises foram feitas a partir do material final produzido pelos grupos de professores, entregue no último encontro.

\section{Unidade 1}

A situação problema proposta foi: "A partir das principais características dos combustíveis (álcool e gasolina), avaliar as vantagens e desvantagens de cada um". Os autores propuseram algumas questões para iniciar o estudo da unidade: "Álcool X Gasolina. Qual combustível você utilizaria para abastecer o seu carro: o álcool combustível ou a gasolina? Justifique sua escolha". "Será o álcool uma melhor alternativa à gasolina em termos ambientais e energéticos"? 
Essa unidade pode ser compreendida como sendo composta por três partes: problematização, informações e ampliação dos conhecimentos e tomada de posição. A primeira parte se inicia com um texto que tem o objetivo de trazer à tona conhecimentos que os alunos têm sobre o petróleo e sobre o uso de etanol, bem como introduzir conceitos relativos à matriz energética brasileira, etanol combustível, problemas ambientais causados pelo uso de combustíveis. $O$ texto é acompanhado de questões para sua compreensão. A segunda parte da unidade tem a finalidade de ampliar os conhecimentos dos alunos. Nesta parte, é apresentado um texto, abordando a função química álcool (estrutura, nomenclatura, isomeria). São propostas duas atividades experimentais, uma envolvendo a comparação da queima de combustíveis e outra sobre a produção do etanol por fermentação de garapa; são previstas aulas para a apresentação de conceitos (propriedades de álcoois, calor de combustão). As atividades experimentais apresentam roteiros e são acompanhadas de questões para análise dos dados. São propostas aulas de exercícios para que os alunos apliquem os conceitos tratados. Além disso, são apresentados dois conjuntos de três textos que tratam, respectivamente, de vantagens do etanol combustível e de impactos ambientais causados pela produção e uso do etanol. Esses textos são subsídios para a parte final da unidade, sendo proposta a confecção de um vídeo ou a realização de um júri, em que os alunos devem apresentar argumentos a favor e contra o uso de etanol e de gasolina.

As figuras $4 \mathrm{a}$ e $4 \mathrm{~b}$ apresentam os conteúdos CTSA abordados na unidade, elaborados, respectivamente, pelos professores autores e pelos pesquisadores.

Figuras 4 a e $4 \mathrm{~b}$ - Conteúdos de CTSA, apresentados pelos professores autores (4a) e pelos pesquisadores (4b), da unidade didática 1.

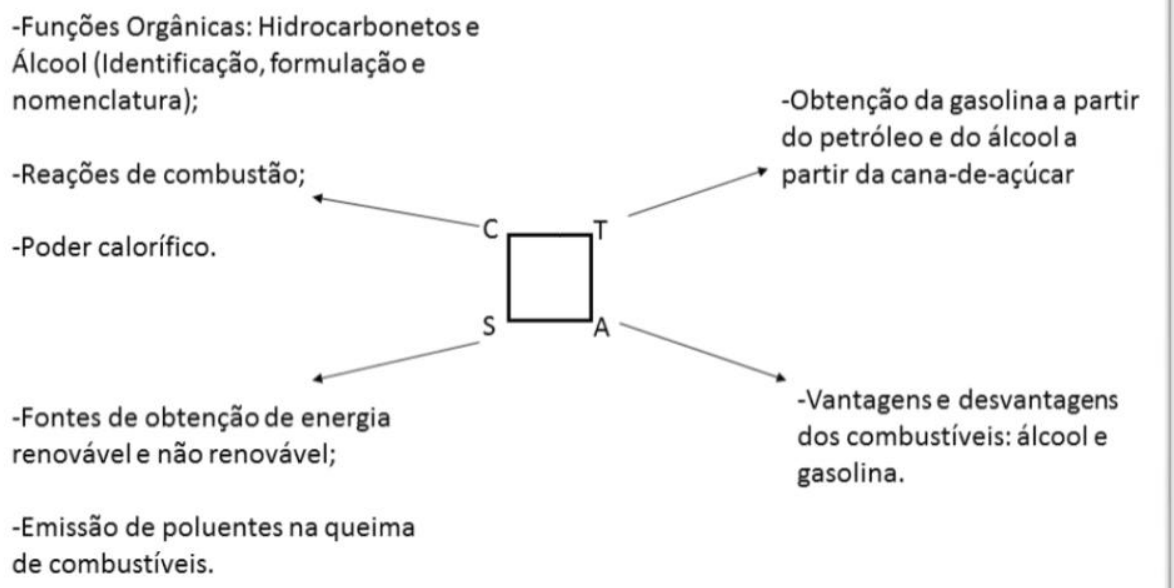


Origem, composição e uso do petróleo e seus derivados

Funções químicas, fórmulas estruturais, propriedades

físico-químicas, isomeria, forças de interação

intermoleculares: hidrocarbonetos, álcool

Temperatura de fulgor

Combustão completa e incompleta

Reações endo e exotérmicas

Entalpia, Poder calorífico

Fermentação alcoólica

Ciclos biogeoquímicos: ciclo do carbono e ciclo do

nitrogênio, Fixação de nitrogênio, desnitrificação

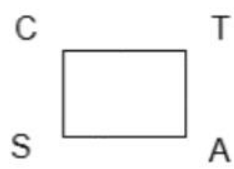

Matriz energética

Problemas econômicos, estratégicos e geopolíticos

relacionados ao petróleo

Substituição de culturas agrícolas pode provocar

desabastecimento de certos tipos de alimentos

Produção de gases tóxicos que podem afetar a

saúde de seres vivos e provocar transformações em

diversos materiais

Problemas trabalhistas, principalmente dos

cortadores de cana

demanda energética e o consumismo exagerado,

com diversas consequências sócio-ambientais

Desenvolvimento sustentável

Efeito estufa

Comparação entre álcool e

gasolina como emissores de

dióxido de carbono

Poluição do ar devido a

emissão de gases NQx

Poluição das águas

Eutrofização de rios e

córregos

Pode-se perceber que os autores foram mais sucintos em relacionar os conteúdos CTSA em seu esquema (figura 4a). Com a leitura da unidade, verificouse que os conteúdos de ciência e sociedade apresentados pelos autores estão ali contidos. Os conteúdos de tecnologia citados no esquema - obtenção da gasolina a partir do petróleo e do álcool a partir da cana-de-açúcar - não foram desenvolvidos na unidade, constando apenas os nomes dos processos de obtenção: do petróleo - destilação fracionada - e do álcool - fermentação alcoólica. Isso pode indicar certa dificuldade em incorporar no ensino aspectos tecnológicos, e que os autores acreditam que apenas citar o nome do processo pode ser considerado uma abordagem que apresenta esses aspectos. Os autores, portanto, parecem considerar que tratar no ensino de aspectos tecnológicos, seja eles se referirem estritamente aos processos estudados e os aspectos mais amplos, que possibilitem refletir sobre o uso dessas tecnologias para um desenvolvimento sustentável (SANTOS; MORTIMER, 2000), têm uma importância secundária, frente aos conteúdos científicos.

Ainda, o aspecto ambiental mencionado pelos autores - vantagens e desvantagens dos combustíveis: álcool e gasolina - não especifica exatamente um conteúdo ambiental, mas trata da situação-problema da unidade. Com a leitura, identificaram-se os conteúdos relacionados a questões ambientais que constam do esquema elaborado pelos pesquisadores.

A situação problema que dá início à unidade é tratada ao longo das atividades propostas. Os dois experimentos sugeridos apresentam relação direta com o tema (nível 2), pois tratam da comparação do poder calorífico de etanol e gasolina e da obtenção de etanol por fermentação, sendo classificados como de natureza científica, pois as questões de análise estão focadas nos conhecimentos químicos. Estão apresentadas, a seguir, exemplos de questões formuladas para explorar os experimentos. 
Qual é o poder calorífico da gasolina? Qual é a quantidade de calor produzida na queima de 51 litros de gasolina? (exp. 1)

\section{(exp. 2)}

Quais são os produtos do processo de fermentação realizado pela levedura?

Mesmo sendo de natureza científica, considerou-se que o primeiro experimento dá subsídios para ampliar o entendimento da situação problema, pois permite comparar a eficiência energética dos combustíveis. Os textos apresentados contribuem para ampliar conhecimentos sobre a situação problema, envolvendo questões como a produção de gás carbônico pelos combustíveis, destino do vinhoto na produção de etanol, possíveis problemas causados pela substituição da gasolina pelo etanol, entre outras. A atividade final, produção de um vídeo sobre um dos combustíveis mostrando as vantagens de seu uso, ou um júri em que dois grupos de alunos defenderiam, respectivamente, cada um dos combustíveis, retoma a situação problema inicial, com possíveis debates, embora não tenha havido um convite explícito para que cada aluno avaliasse e julgasse a problemática em estudo.

Essa unidade didática, ao ser analisada, apresentou características que permitiram classificá-la como descrição científica de fatos e processos (vide quadro 7), pois a maioria dos elementos analisados se enquadra nos critérios estabelecidos, como é mostrado no quadro 8.

Quadro 8-Caracterização da unidade didática 1 para conhecer sua perspectiva de contextualização.

\begin{tabular}{|c|c|c|c|c|c|c|}
\hline $\begin{array}{c}\text { Unida- } \\
\text { de di- } \\
\text { dática }\end{array}$ & $\begin{array}{c}\text { Proble- } \\
\text { matiza- } \\
\text { ção }\end{array}$ & $\begin{array}{c}\text { Enfoque } \\
\text { CTSA na } \\
\text { visão geral } \\
\text { do tema }\end{array}$ & $\begin{array}{c}\text { Conhecimento } \\
\text { específico de } \\
\text { química em } \\
\text { relação ao tema }\end{array}$ & $\begin{array}{c}\text { Experimenta- } \\
\text { ção (relação } \\
\text { com o tema, } \\
\text { natureza }\end{array}$ & $\begin{array}{c}\text { Caracte- } \\
\text { rísticas das } \\
\text { atividades }\end{array}$ & $\begin{array}{c}\text { Nova visão do } \\
\text { tema }\end{array}$ \\
\hline 1 & $\begin{array}{c}\text { contí- } \\
\text { nua }\end{array}$ & C>TSA & relação média & $\begin{array}{c}\text { relação dire- } \\
\text { ta, científico }\end{array}$ & $\begin{array}{c}\text { não-proble- } \\
\text { matizadoras }\end{array}$ & $\begin{array}{c}\text { busca resolver } \\
\text { o problema }\end{array}$ \\
\hline
\end{tabular}

Os textos utilizados nessa unidade merecem destaque por não apresentarem ênfase em aspectos científicos, mas sociais e ambientais. Além disso, foram escolhidos textos que apresentam pontos de vistas diferentes em relação ao uso de combustíveis alternativos em substituição aos combustíveis fósseis, pois há opiniões diferentes quanto aos benefícios que essa substituição pode ocasionar. Outro aspecto importante é a retomada da situação-problema, pois os autores sugerem atividades que buscam proporcionar aos alunos emitirem, coletivamente, opiniões sobre a escolha do etanol ou da gasolina como combustível. O uso desses textos e atividades parece indicar que os professores, autores dessa unidade didática, incorporaram algumas das ideias discutidas ao longo do curso de formação, ou seja, o uso das relações CTSA para desenvolver atitudes mais conscientes nos estudantes (ACEVEDO-DIAZ, 1996). Entretanto, os professores não conseguiram atingir níveis mais elaborados de contextualização no seu material didático.

Quanto aos critérios que caracterizam esse material como CTSA (SANTOS, 2001), o único abordado diz respeito ao balanço de pontos de vista, pois apresenta tanto textos que defendem o uso de biocombustíveis como solução para diminuir o problema do aumento do efeito estufa, como outros que consideram que esse 
uso não resolverá esse problema ambiental e trará outros problemas futuros. Embora os alunos, para os quais a unidade seria aplicada, tenham sido convidados a debater diferentes visões, não transparece, na unidade, aspectos relativos aos critérios responsabilidade e ações responsáveis, pois não são incentivados a apresentar suas posições pessoais, a refletir sobre seu papel na sociedade e sua participação no ecossistema ou a propor ações tendo em vista o problema em estudo. O critério relações mútuas CTSA parece estar presente superficialmente, pois, embora não seja estabelecida claramente uma relação CTSA, no conjunto de textos apresentados tais relações poderiam ser construídas. Freitas e Santos (2004) obtiveram resultados diferentes ao analisar as unidades produzidas por professores, pois os materiais elaborados se aproximavam das características CTS apontadas por Santos (2001).

\section{Unidade 2}

A situação problema proposta foi: "Como reduzir a emissão de poluentes atmosféricos originados pela utilização de combustíveis". Os autores não apresentaram questões subsidiárias, ao proporem o tema.

Essa unidade pode ser dividida em duas partes: uma, que introduz a situação problema e apresenta conteúdos relacionados ao tema, e outra, focada na tomada de posição. Inicialmente, é proposta a apresentação de dois vídeos curtos, um para sensibilizar os alunos quanto à problemática do uso de combustíveis fósseis e seus efeitos, como poluição e aquecimento global, e outro sobre opiniões de motoristas quanto ao uso do álcool ou da gasolina como combustível automotivo. A seguir, é apresentado um texto sobre tipos de energia, para que o aluno relembre o que já conhece sobre o assunto, sendo apresentadas questões não apenas sobre o entendimento do texto, mas também para iniciar uma discussão sobre a situação problema, como é ilustrado na questão a seguir.

Qual o comportamento ideal do ser humano em relação ao uso de energias? Renovável ou não renovável? Explique.

Dois experimentos são propostos, um que compara os processos de combustão do álcool e da gasolina, para que o aluno perceba a formação de fuligem na queima deste último e não na do etanol, e o segundo experimento trata da combustão da madeira. Em ambos os experimentos o foco é o conhecimento químico, como mostram as questões apresentadas aos alunos. Para complementar as informações, um conjunto de três textos é apresentado aos alunos, dois deles abordando aspectos das reações de combustão, completa e incompleta, e da linguagem e representação dessas transformações, e o terceiro, abordando a separação de produtos formados na queima da madeira. Os textos são acompanhados de questões visando o entendimento das informações fornecidas. A seguir, apresentam-se alguns exemplos.

O que é fuligem? (texto 1).

Descreva o processo de destilação a seco (texto3).

Na parte final da unidade, cujo foco é a retomada do problema inicial, é composta por um texto sobre poluição e qualidade do ar, questões para o entendimento e um debate entre dois grupos, um contra e outro a favor da ideia de poluição como indicador de progresso de uma nação. 
As figuras $5 a$ e $5 \mathrm{~b}$ apresentam os conteúdos CTSA abordados na unidade, elaborados, respectivamente, pelos autores e pelos pesquisadores.

Figuras 5a e 5b -- Conteúdos de CTSA apresentados pelos autores (a) e pelos pesquisadores (b) da unidade didática 2.

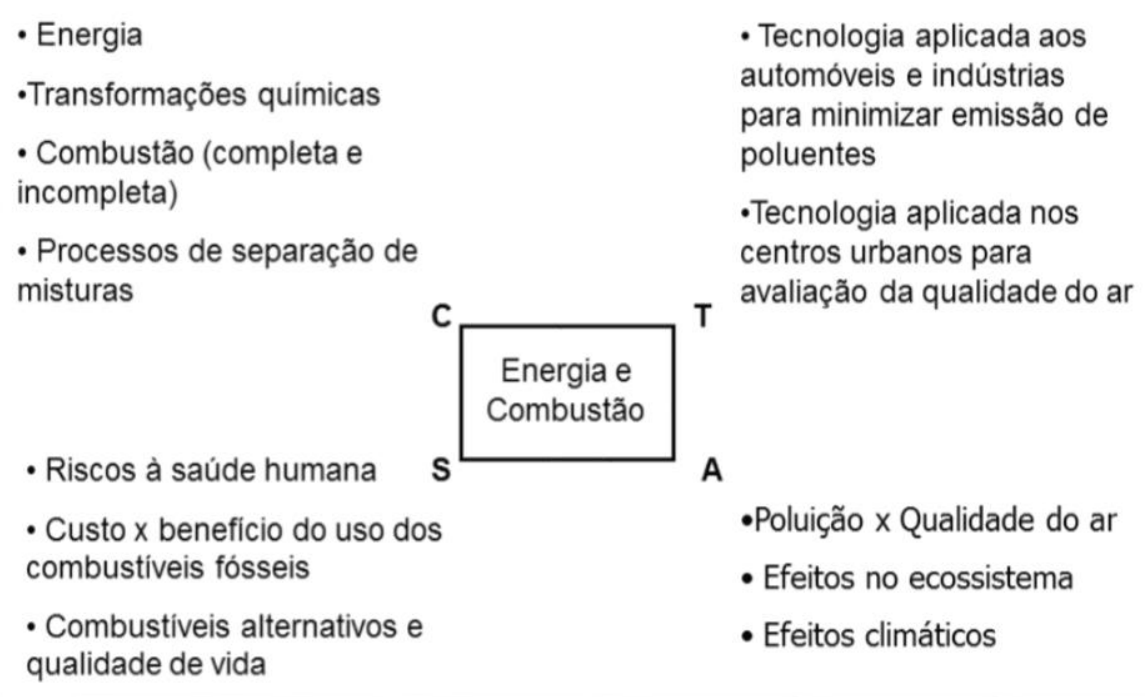

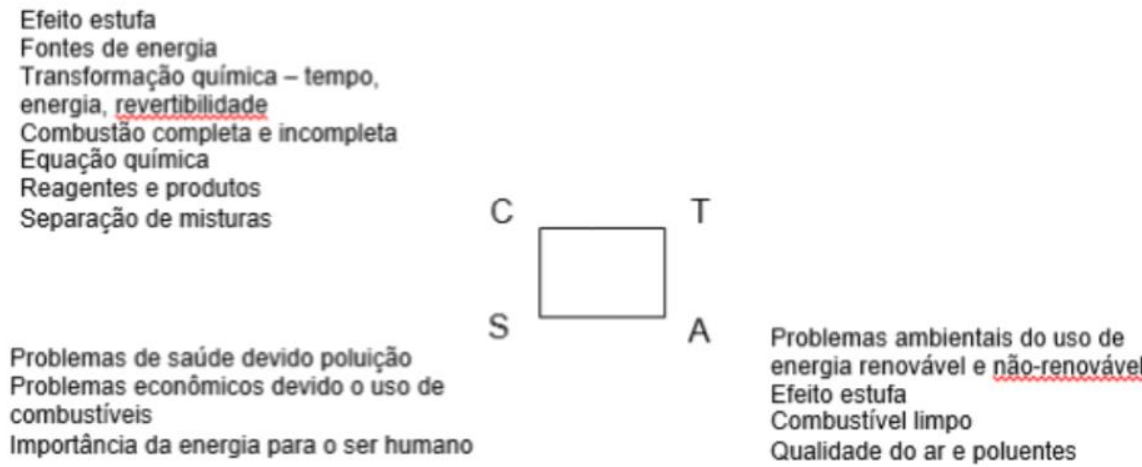

Problemas de saúde devido poluição

Problemas econômicos devido o uso de combustiveis

Importância da energia para o ser humano

Problemas ambientais do uso de energia renovável e não-renováve Efeito estufa

Combustivel limpo

Qualidade do ar e poluentes

Comparando-se os dois esquemas (figuras $5 a$ e $5 b$ ), percebe-se que os conteúdos de Ciência, Sociedade e Ambiente são semelhantes, com poucas alterações, mas os conteúdos de Tecnologia, apesar de estarem indicados pelos autores, não foram encontrados em nossa leitura da unidade didática. Os conteúdos sobre tecnologia apresentados pelos professores em seu esquema "Tecnologia aplicada aos automóveis e indústrias para minimizar emissão de poluentes" e "Tecnologia aplicada nos centros urbanos para avaliação da qualidade do ar" - embora citados, não são abordados na unidade, nem há referência a quais gases são considerados para determinar a qualidade do ar e os efeitos na saúde ao serem atingidos determinados níveis medidos, não sendo tratados aspectos tecnológicos relacionados a esses assuntos. Isso parece indicar não haver um entendimento do que seja tratar conteúdos de tecnologia em materiais didáticos, pois não são discutidas técnicas utilizadas para realizar essas medidas e nem mesmo os equipamentos adequados para esse fim e como otimizá- 
los, o que poderia ser esperado sob a óptica de uma visão mais restrita de tecnologia (SANTOS; MORTIMER, 2000). Assim, na figura 5b, elaborada por nós, não se pode contemplar o item tecnologia.

A situação problema inicial é tratada ao longo das atividades propostas, principalmente em alguns dos textos e na atividade final. Os experimentos apresentam relação fraca com o tema, uma vez que, embora tratem de combustíveis, não exploram aspectos do tema, sendo utilizados principalmente para o conhecimento de fenômenos de combustão. Os textos abordam alguns conhecimentos específicos que não se relacionam diretamente com a temática tratada, como identificação de reagentes e produtos em uma equação química, conceito de transformação química. Assim, o conhecimento químico apresentado foi considerado como tendo uma relação média com o tema.

Após a análise de todos os elementos pedagógicos da unidade didática, podese caracterizá-la como descrição científica de fatos e processos, como é mostrado no quadro 9.

Quadro 9 - Caracterização da unidade didática 2 para conhecer sua perspectiva de contextualização.

\begin{tabular}{|c|c|c|c|c|c|c|}
\hline $\begin{array}{c}\text { Unidade } \\
\text { didática }\end{array}$ & $\begin{array}{c}\text { Proble- } \\
\text { matiza- } \\
\text { ção }\end{array}$ & $\begin{array}{c}\text { Enfoque } \\
\text { CTSA na } \\
\text { visão geral } \\
\text { do tema }\end{array}$ & $\begin{array}{c}\text { Conhecimento } \\
\text { específico de } \\
\text { química em } \\
\text { relação ao tema }\end{array}$ & $\begin{array}{c}\text { Experimenta- } \\
\text { ção (relação } \\
\text { com o tema, } \\
\text { natureza }\end{array}$ & $\begin{array}{c}\text { Caracte- } \\
\text { rísticas das } \\
\text { atividades }\end{array}$ & $\begin{array}{c}\text { Nova } \\
\text { visão do } \\
\text { tema }\end{array}$ \\
\hline 2 & $\begin{array}{c}\text { Contí- } \\
\text { nua }\end{array}$ & C>TSA & relação média & $\begin{array}{c}\text { relação fraca, } \\
\text { científico }\end{array}$ & $\begin{array}{c}\text { não-proble- } \\
\text { matizadoras }\end{array}$ & $\begin{array}{c}\text { retoma o } \\
\text { tema }\end{array}$ \\
\hline
\end{tabular}

A problematização foi considerada contínua, pois é apresentada desde o início, por meio de um vídeo que mostra imagens relativas a problemas ambientais provocados pela poluição, principalmente, devido à queima de combustíveis, e que busca alertar as pessoas para os problemas, indicando ações para evitá-los. Os textos, com exceção do final, abordam apenas aspectos da produção de poluentes e auxiliam pouco na resolução do problema proposto, mas as questões apresentadas procuram tratar do tema. Mesmo tendo sido classificada como descrição científica de fatos e processos, essa unidade mostra um certo avanço em relação ao entendimento sobre a contextualização, pois algumas das questões finais propunham situações para que os alunos julgassem e tomassem decisões. Um debate final é proposto, em que se deve avaliar a poluição como um indicativo de desenvolvimento de uma região. Pode-se, assim, sugerir uma aproximação com a visão de compreensão da realidade social.

Quanto às características de um material com orientação CTSA (SANTOS, 2001), essa unidade didática apresenta parcialmente os seguintes critérios: responsabilidade, influências mútuas CTS, relações com as questões sociais, balanço de pontos de vista, tomada de decisões e resolução de problema. Segundo nossa análise, o material explicitamente não desenvolve a compreensão dos alunos de sua interdependência como membro da sociedade; não apresenta claramente as relações entre ciência, tecnologia, sociedade e ambiente; não estabelece claramente as relações do desenvolvimento científico e tecnológico com a sociedade; apresenta poucos pontos de vistas diversos sobre as questões propostas; e não parece levar o aluno a resolver a situação-problema. 


\section{Unidade 3}

A situação problema proposta foi: "Relação custo benefício entre etanol e gasolina", com apresentação de questões iniciais aos alunos para conhecimento de suas ideias (o que é combustível, diferença entre combustível fóssil e biocombustível, relação entre aquecimento global e uso de combustível). Tal situação é explorada ao longo da atividade, embora algumas das atividades propostas tenham foco no conteúdo de química (nomenclatura de hidrocarbonetos e de álcoois, leis ponderais, por exemplo), e finaliza com a proposta de um debate entre dois grupos, cada qual apresentando argumentos em defesa do uso de um dos combustíveis.

Essa unidade pode ser dividida em três partes: uma inicial, que introduz a situação problema, a segunda apresenta conteúdos químicos específicos, e a última, focada na retomada da situação problema. A unidade se inicia com o levantamento prévio das ideias dos alunos sobre o que é combustível, diferença entre combustível fóssil e biocombustível, relação entre aquecimento global e uso de combustível. Além disso, propõe o trabalho com um texto sobre a tecnologia em carros flex, apresentando questões para o entendimento do texto. A seguir, são propostas aulas expositivas para abordar os seguintes conteúdos: obtenção de álcool e da gasolina; leis ponderais; reação de combustão e problemas ambientais causados pela combustão. As duas atividades experimentais planejadas tratam, respectivamente, de determinação da energia liberada na queima de etanol e de gasolina, e da comparação de formação de fuligem na combustão desses materiais. No primeiro experimento citado, o aluno é convidado a calcular o poder calorífico, sendo dado, passo a passo, o procedimento para tal. No segundo, as questões apresentadas tanto exploram os dados, quanto procuram fazer com que o aluno relacione suas observações com outras situações, como ilustra a questão a seguir.

Que outros processos você conhece que produzem fuligem e não foram citados aqui? (exp. 2)

Por que, muitas vezes, em tuneis longos, se encontram placas com os dizeres: "desligue o motor em caso de congestionamento"? (exp. 2)

Na parte final, é proposta a leitura de um texto sobre "verdades e mitos sobre os carros flex", em que são apresentadas e explicadas algumas dúvidas sobre o funcionamento dos carros flex, e é sugerido aos alunos que calculem a razão entre o custo dos combustíveis e estimem se é vantajoso o abastecimento com etanol ou gasolina. Encerrando a unidade, há a proposta de um tribunal no qual os alunos argumentem sobre os prós e contras do uso dos combustíveis álcool e gasolina.

As figuras $6 a$ e $6 \mathrm{~b}$ apresentam os conteúdos CTSA abordados na unidade, elaborados, respectivamente, pelos autores e pelos pesquisadores após a leitura da unidade. 
Figuras $6 a$ e $6 \mathrm{~b}$ - Conteúdos de CTSA elaborados pelos autores (a) e pelos pesquisadores (b) da unidade didática 3.

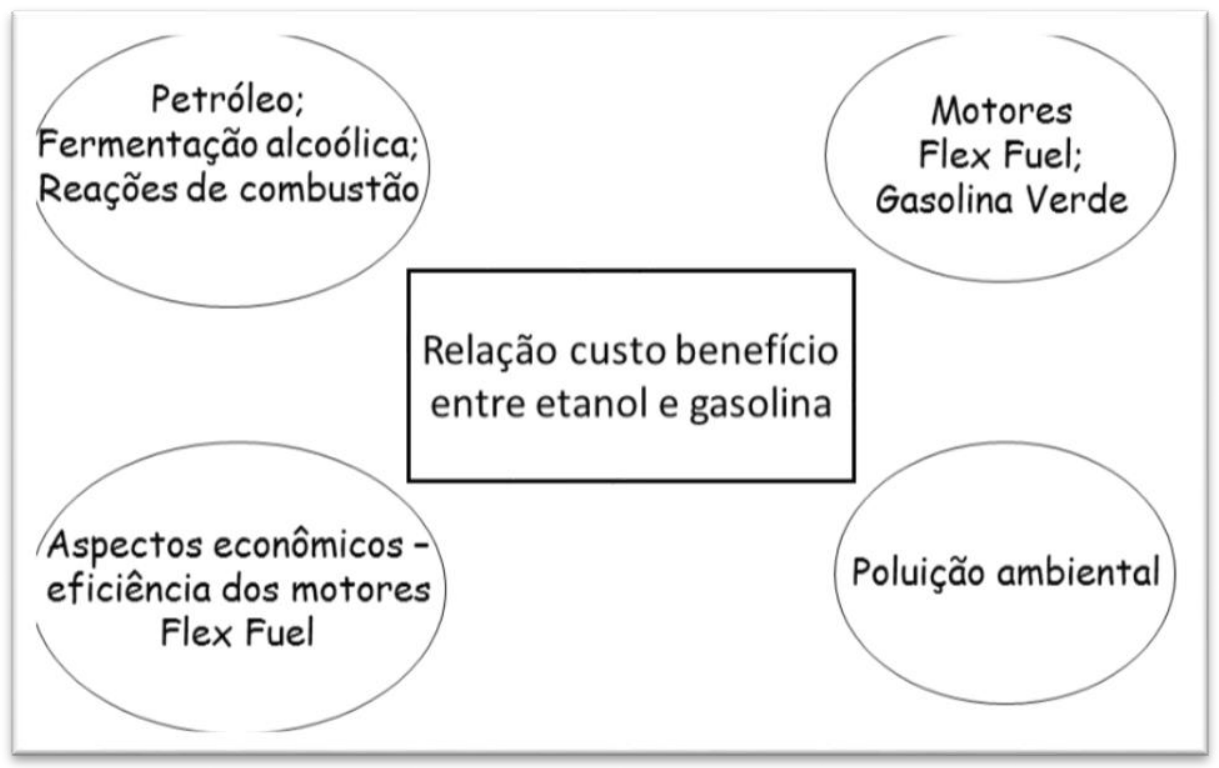

Composição do petróleo

Craqueamento, Reforma catalítica

Octanagem

Fermentação alcoólica

Aplicações do etanol

Leis ponderais: Lei de Lavoisier, Lei de

Proust, Lei de Dalton, Lei de Gay-Lussac

Combustão completa e incompleta

Perspectivas de uso de carros flex.

bicombustiveis e triflex; aspectos econômicos

relacionados a esses veículos

Início da indústria do petróleo no mundo e no

Brasil

Histórico da produção de álcool no Brasil e início

de seu uso como combustivel

Problemas de saúde devido ao etanol e metanol

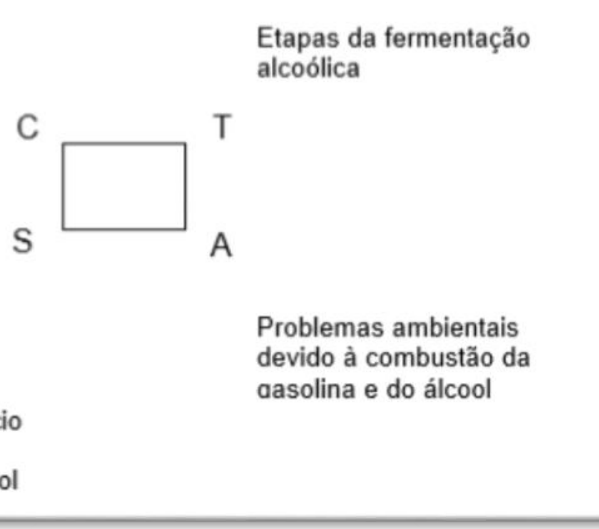

Como se pode perceber, ao se compararem os esquemas (figuras 6a e 6b), os autores não declararam todos os conteúdos CTSA tratados na unidade, talvez querendo mostrar o que julgaram mais importante. Constatou-se, após a leitura, que os conteúdos de tecnologia apresentados na figura 6a dos autores não são abordados na unidade, mas há uma descrição resumida do processo utilizado na fermentação alcoólica, podendo ser considerado um conteúdo tecnológico presente no material. Embora pareça haver dificuldade em relacionar aspectos tecnológicos ao tema, esta unidade se destaca, em relação às demais, por abordar alguns desses aspectos. Não se pode deixar de considerar, entretanto, que essa abordagem pode reforçar uma ideia de conhecimento tecnológico como fornecedor de técnicas sem que sejam discutidas implicações sociais e ambientais do uso de tais técnicas (FRACALANZA; MEGID, 2006).

Após a classificação dos elementos pedagógicos dessa unidade, pode-se caracterizá-la também como descrição científica de fatos e processos (quadro 10). 
Quadro 10 - Caracterização da unidade didática 3 para conhecer sua perspectiva de contextualização.

\begin{tabular}{|c|c|c|c|c|c|c|}
\hline $\begin{array}{c}\text { Unidade } \\
\text { didática }\end{array}$ & $\begin{array}{c}\text { Proble- } \\
\text { matiza- } \\
\text { ção }\end{array}$ & $\begin{array}{c}\text { Enfoque } \\
\text { CTSA na } \\
\text { visão geral } \\
\text { do tema }\end{array}$ & $\begin{array}{c}\text { Conhecimento } \\
\text { específico de } \\
\text { química em } \\
\text { relação ao tema }\end{array}$ & $\begin{array}{c}\text { Experimen- } \\
\text { tação (relação } \\
\text { com o tema, } \\
\text { natureza) }\end{array}$ & $\begin{array}{c}\text { Caracte- } \\
\text { rísticas das } \\
\text { atividades }\end{array}$ & $\begin{array}{c}\text { Nova visão } \\
\text { do tema }\end{array}$ \\
\hline 3 & $\begin{array}{c}\text { contí- } \\
\text { nua }\end{array}$ & C>TSA & relação média & $\begin{array}{c}\text { relação direta, } \\
\text { científico }\end{array}$ & $\begin{array}{c}\text { não-proble- } \\
\text { matizadoras }\end{array}$ & $\begin{array}{c}\text { retoma o } \\
\text { tema }\end{array}$ \\
\hline
\end{tabular}

Algumas atividades merecem destaques e podem ser consideradas avanços em relação ao ensino dito tradicional, pois o estudo é iniciado pelo levantamento das ideias prévias dos alunos sobre o tema abordado, apresenta textos que podem auxiliar o aluno a entender as implicações ambientais do uso de álcool ou gasolina como combustível, mostrando dados de emissão de gás carbônico emitidos pela produção e uso do etanol e da gasolina e, para encerrar a unidade, é proposta a simulação de um tribunal para que os alunos criem argumentos tanto a favor como contra o uso dos dois tipos de combustíveis (álcool e gasolina). Essas atividades podem proporcionar aos alunos pontos de vistas diferentes em relação à problemática abordada. Ainda, é proposta uma aula expositiva para que os alunos tenham informações sobre aspectos tecnológicos relativo ao processo de fermentação alcoólica.

A respeito das competências e habilidades que materiais didáticos CTS deveriam desenvolver, conforme proposto por Santos (2001), essa unidade apresenta em seus textos algumas relações CSA; os balanços de ponto de vista não são apresentados claramente no material, mas há uma tentativa de que os alunos busquem essa diversidade de pontos de vistas ao proporem argumentos a favor e contra o uso de etanol ou gasolina como combustível automotivo. Entretanto, não desenvolve responsabilidade e nem ações responsáveis, pois não é solicitado que os alunos se posicionem individual ou coletivamente sobre uma questão problema, já que a intenção da unidade é apresentar a relação custo benefício no uso de gasolina ou álcool como combustível. Portanto, relacionado a esses critérios, essa unidade didática não pode ser considerada como um material curricular CTS, uma vez que são poucas as contribuições pedagógicas que permitem aos estudantes o desenvolvimento de competências e atitudes tendo em vista uma formação mais crítica e responsável.

As perspectivas CTS que cada unidade apresentou foram comparadas com as visões que os professores manifestaram no primeiro encontro. Nesse encontro, os professores foram convidados a descrever uma atividade que ele considerava contextualizada e aplicava em sala de aula, e explicar o que entendiam de contextualização. As ideias apresentadas pelos professores foram classificadas sempre que possível nas perspectivas CTS (quadro 1). O quadro 11 apresenta a perspectiva de contextualização da unidade e as ideias iniciais dos professores que a elaboraram (denominados de professor A, B e assim por diante).

Quadro 11 - Perspectivas de contextualização das unidades didáticas e as ideias iniciais sobre contextualização dos professores autores de cada unidade didática.

UD

Perspectiva de contextualização

Ideias iniciais dos professores sobre contextualização da unidade 


\begin{tabular}{|c|c|l|l|}
\hline 1 & $\begin{array}{c}\text { Descrição científica } \\
\text { de fatos e } \\
\text { processos }\end{array}$ & $\begin{array}{l}\text { professor A Exemplificação do conhecimento } \\
\text { professor B Descrição científica de fatos e processos } \\
\text { professor C Transformação da realidade social }\end{array}$ \\
\hline \multirow{2}{*}{2} & $\begin{array}{c}\text { Descrição científica } \\
\text { de fatos e } \\
\text { processos }\end{array}$ & $\begin{array}{l}\text { professor D Outro } \\
\text { professor E Problematização da realidade social } \\
\text { professor F Exemplificação do conhecimento } \\
\text { professor G Descrição científica de fatos e processos }\end{array}$ \\
\hline \multirow{3}{*}{3} & $\begin{array}{c}\text { professor M Exemplificação do conhecimento } \\
\text { professor N Problematização da realidade social } \\
\text { professor O Descrição científica de fatos e processos } \\
\text { de fatos e } \\
\text { processos }\end{array}$ & $\begin{array}{l}\text { professor P Exemplificação do conhecimento } \\
\text { professor Q Compreensão da realidade social }\end{array}$ \\
\hline
\end{tabular}

Pode-se notar que, enquanto nas unidades se manifesta uma perspectiva de contextualização como descrição científica de fatos e processos, entre os elaboradores, as concepções são diferenciadas, incluindo aquelas que apresentam nível de complexidade maior, como a compreensão e a transformação da realidade social. Na elaboração da unidade 2 , dois dos quatro participantes apresentam ideias mais avançadas sobre contextualização social dos conhecimentos e na unidade 3, dois entre os cinco participantes. Ter-se-ia, assim, a possibilidade de influência dessas concepções na construção dos materiais, nesses grupos. Pode-se conjecturar, portanto, que tais ideias não foram acolhidas pelo grupo de forma ampla, mas se manifestaram em algumas das atividades, como na proposta da simulação de um tribunal para avaliação do uso de combustíveis (unidade 3).

\section{CONCLUSÕES}

Embora tenham sido discutidos ao longo do curso aspectos que procuravam expor ideias mais avançadas em relação à perspectiva de contextualização, nenhum desses grupos conseguiu atingir algum desses níveis mais elaborados. Mesmo assim, há que se destacar que essas unidades buscaram desenvolver temas que não são muito discutidos nas aulas de química do ensino médio e muitos desenvolveram questões que buscavam resolver situações-problemas apresentadas no início de suas unidades didáticas, além de abordar aspectos como julgamento e tomada de decisões por parte dos alunos relativos ao tema tratado. Além disso, algumas atividades podem ser consideradas avanços em relação ao ensino tradicional, tais como textos que apresentam questões sociais e ambientais e a proposição de debates, pesquisas e elaboração de cartazes com possíveis respostas ao problema proposto, propiciando aos alunos criarem argumentos para explicitar seus pontos de vista.

Conhecimentos referentes à tecnologia foram os mais difíceis para os professores, pois a tecnologia foi tratada em uma única unidade, na qual foram abordados apenas aspectos técnicos operacionais, ou seja, os processos envolvidos. Essa é uma visão restrita de tecnologia, pois ignora aspectos organizacionais e culturais a ela pertinentes. Não há uma compreensão da tecnologia como conhecimento que pode possibilitar o ser humano controlar e modificar o mundo ou mesmo refletir sobre o significado de consumir e produzir aparatos para serem utilizados pela sociedade (SANTOS; MORTIMER, 2000; AMARAL; FIRME, 2008). 
Os materiais elaborados revelaram dificuldades apresentadas pelos professores em estabelecer inter-relações entre Ciência, Tecnologia, Sociedade e Ambiente. Geralmente, os conteúdos científicos foram bem desenvolvidos, mas não são exploradas as relações de como a ciência influencia a sociedade, a tecnologia e o ambiente e como é influenciada por esses campos. O estabelecimento dessas relações permitiria que se atingissem níveis mais complexos de contextualização, contribuindo para a formação de alunos mais cientes de seu papel na sociedade, que pudessem tomar decisões e participar de transformações na sociedade (LINSINGEN, 2007).

Essas unidades não foram consideradas materiais curriculares CTSA quando se utilizam os critérios propostos por Santos (2001), pois não procuraram desenvolver aspectos importantes, tais como responsabilidade, ações responsáveis, influências mútuas. Apenas o aspecto relativo a balanço de pontos de vista foi enfatizado. Não se pode negar, entretanto, que os professores avançaram na proposição de seus materiais, uma vez que não se restringiram a desenvolver conteúdos científicos, procurando abordar aspectos de natureza social, ambiental e econômicos.

Assim, processos de formação continuada com enfoque na produção de materiais pelos próprios professores e que aprofundem a compreensão sobre abordagens CTSA no ensino, podem contribuir para a reflexão sobre suas práticas pedagógicas e troca de experiências com seus pares e também com pesquisadores. A elaboração de materiais com características CTSA parece ser um bom exercício para que o professor possa diminuir sua dependência de livros didáticos, pensando em seu desenvolvimento profissional de forma mais ampla. 


\title{
STSE-oriented instructional materials produced by chemistry teachers
}

\begin{abstract}
This paper aims to analyse instructional materials produced by chemistry teachers who participate in in-service training course, which explores the context-based approach with regard to STSE perspectives. Three materials focused in renewable and non-renewable fuels were analysed. The analysis took into account five context-based perspectives: scientific concepts exemplification with daily life facts, scientific description of facts and process linked to chemistry, questioning social reality, comprehension of social reality and transforming social reality. The potential of the material in developing citizenship attitudes was also analysed. The three instructional materials were classified as scientific description of facts and process as they are mainly focused on chemistry subjects. Contents exploring technological issues were absent in two of the instructional materials. However, there were advances as they presented texts, which included social, economic environmental aspects and their relationships. The production of instructional materials by teachers was a good methodology for in-service chemistry teachers' courses.
\end{abstract}

KEYWORDS: In-service training course. Chemistry teaching. Context-based teaching approach. 


\section{REFERÊNCIAS}

ACEVEDO-DIAZ, J. A. Cambiando la práctica docente en la enseñanza de las ciencias a través de CTS. Revista Borrador, v. 13, 1996. Disponível em:

<http://www.campus-oei.org/salactsi/acevedo2.htm>. Acesso em: 20 Jul. 2010.

ACEVEDO-DÍAZ, J. A. Reflexiones sobre las finalidades de la enseñanza de las ciencias: educación científica para la ciudadanía. Revista Eureka sobre Enseñanza y Divulgación de las Ciencias, Cádiz, v. 01, n. 01, 2004, p. 3-16. Disponível em: <http://venus.uca.es/eureka/revista/Volumen1/Numero_1_1/ Educa_cient_ciudadania.pdf>. Acesso em: 21 jul. de 2010.

ACEVEDO DIAZ, J. A; VÁZQUEZ-ALONSO, Á.; MARTÍN, M.; OLIVA, J. M.; ACEVEDO, P.; PAIXÃO, M. F.; MANASSERO-MAS, M. A. Naturaleza de la Ciencia y Educación Científica para la participación ciudadana: una revisión crítica. Revista Eureka sobre Enseñanza y Divulgación de las Ciencias, Cádiz, v. 02, n. 02, 2005, p. 121140. Disponível em: http://www.redalyc.org/pdf/920/92020201.pdf. Acesso em 12 de junho de 2017.

AIKENHEAD, G. S. The social contract of science: implications for teaching science. In: SOLOMON, Joan e AIKENHEAD, Glen S. (Eds.). STS education - International perspectives on reform. New York: Teachers College Press, 1994.

AIKENHEAD, G. S.; RYAN, A. G. The development of a new instrument: views on Science-Technology-Society. Science Education, v. 76, n. 5, 1992.

AKAHOSHI, Luciane Hiromi. Uma Análise de Materiais Instrucionais com Enfoque CTSA Produzidos por Professores em um Curso de Formação Continuada. Dissertação de Mestrado, Universidade de São Paulo, Programa de Pósgraduação Interunidades em Ensino de Ciências, São Paulo, 2012.

AMARAL, E. M. R.; FIRME, R. N. Concepções de professores de química sobre ciência, tecnologia, sociedade e suas inter-relações: um estudo preliminar para o desenvolvimento de abordagens CTS em sala de aula. Ciência \& Educação, v. 14, n. 2, 2008, p. 251-269.

AULER, D. Alfabetização Cientifico-Tecnológica: um novo "Paradigma"? Ensaio Pesquisa em Educação em Ciências, Belo Horizonte, v. 5, n. 1, 2003, p. 69-83.

AULER, D.; DELIZOICOV, D. Alfabetização Científico-Tecnológica para quê? Ensaio - Pesquisa em Educação em Ciências, Belo Horizonte, v. 3, n. 2, 2001, p. 105-116. 
BERNARDO, J. R. R.; VIANNA, D. M.; FONTOURA, H. A. Produção e consumo da energia elétrica: a construção de uma proposta baseada no enfoque CiênciaTecnologia-Sociedade-Ambiente (CTSA). Ciência \& Ensino, v. 1, n. esp., 2007.

CUNHA, M. B. M., MURITIBA, A. S. O., FERREIRA, A., ALVES, C. A. A., SOTERO, D., SOUZA, D, RIBEIRO, F. J., COSTA, L. B., LIMA, M. M., NOBRE, P. S.S., SILVA, R. J. De que contexto se fala? Análise de livros didáticos de Química para o ensino médio. Anais do XVI Encontro Nacional de Ensino de Química (XVI ENEQ) e X Encontro de Educação Química da Bahia (X EDUQUI), Salvador, Ba, 2012. Disponível em https://portalseer.ufba.br/index.php/anaiseneq2012/article/ view/7860/5575. Acesso em 12 de junho de 2017.

EICHLER, M. L.; DEL PINO, J. C. A produção de material didático como estratégia de formação permanente de professores de ciência. Revista Electrónica de Enseñanza de las Ciencias, v. 9, n. 3, 2010, p 633-656.

FRACALANZA, H.; MEGID, J. Neto. O livro didático de Ciências: problemas e soluções. In: FRACALANZA, Hilário; MEGID, Jorge Neto (orgs.). $O$ Livro Didático de Ciências no Brasil. Campinas: Komedi, 2006, p.153-170.

FREITAS, D.; SANTOS, S. A. M. CTS na produção de materiais didáticos: o caso do projeto brasileiro. Instrumentação para o ensino interdisciplinar das Ciências da Natureza e da Matemática. In: III Seminário Ibérico CTS no Ensino das Ciências. Perspectiva Ciência-Tecnologia-Sociedade na Inovação da Educação em Ciências - III Seminário Ibérico CTS no Ensino das Ciências. Aveiro: Universidade de Aveiro - Departamento de Didáctica e Tecnologia Educativa, 2004, p. 409-413. Disponível em: <http://www.ufscar.br/ ciecultura/denise/evento_3.pdf>. Acesso em: 20 maio 2017.

HOFSTEIN, A., AIKENHEAD, G., RIQUARTS, K. Discussions over STS at the fourth IOSTE Symposium. International Journal of Science education, 10(4), 1988, p. $357-366$.

LAIA, L. R., MILLTIZ, R. A., COMIOTO, T. Um olhar sobre CTS: análise dos livros didáticos de química do PNLD 2015. II Colóquio Luso -Brasileiro de Educação, Joinville, SC, 2016, p. 393-405. Disponível em http://www.revistas.udesc.br/index.php/colbeduca/article/view/8355/6108. Acesso em 16 de junho de 2017.

LIMA, L. P. Currículo de química em foco: reflexões de um grupo colaborativo de professores do Estado de São Paulo, 2016, 194 f. Dissertação (Mestrado em Ciências, área de concentração Ensino de Química) - Programa Interunidades em Ensino de Ciências, Universidade de São Paulo. 
LINSINGEN, I. von. Perspectiva educacional CTS: aspectos de um campo em consolidação na América Latina. Ciência \& Ensino, v. 1, n. esp., 2007.

MARCONDES, Maria Eunice Ribeiro; CARMO, Miriam Possar do; SILVA, Erivanildo Lopes da; SOUZA, Fabio Luiz de; AKAHOSHI, Luciane Hiromi; SUART, Rita de Cássia; MARTORANO, Simone Alves de Assis; TORRALBO, Daniele. Oficinas Temáticas no Ensino Público visando a Formação Continuada de Professores. São Paulo: Imprensa Oficial do Estado de São Paulo, 2007.

MARCONDES, Maria Eunice Ribeiro; CARMO, Miriam Possar do; SUART, Rita de Cássia; SILVA, Erivanildo Lopes; SOUZA, Fabio Luiz; SANTOS Jr., João Batista dos; AKAHOSHI, Luciane Hiromi. Materiais Instrucionais numa Perspectiva CTSA: Uma Análise de Unidades Didáticas Produzidas por Professores de Química em Formação Continuada. Investigações em Ensino de Ciências, 14(2), 2009, p. 281298.

MAZZEU, F. J. C. Uma proposta metodológica para a formação continuada de professores na perspectiva histórico-social. Cad. CEDES, Campinas, v.19, n. 44, 1998. Disponível em: <http://www.scielo.br/scielo.php?script=sci_ arttext\&pid=S0101-32621998000100006\&lng=pt\&nrm=iso>. Acesso em: 20 maio 2017.

SACRISTÁN, J. G. Consciência e aç̧ão sobre a prática como libertação profissional dos professores. In: NÓVOA, Antonio (org.). Profissão Professor. Lisboa: Porto Editora, 2008, p. 63-92.

SANTOS, M. E. V. M. A cidadania na "Voz" dos Manuais Escolares. Lisboa: Livros Horizonte, 2001.

SANTOS, W. L. P.; MORTIMER, E. F. Uma análise de pressupostos teóricos da abordagem C-T-S (Ciência - Tecnologia - Sociedade) no contexto da educação brasileira. Ensaio - Pesquisa em Educação em Ciências, Belo Horizonte, v. 02, n. 02, 2000, p. 133-162.

SANTOS, W. L. P.; SCHNETZLER, R. P. Educação em Química: Compromisso com a Cidadania. Ijuí: Unijuí, 1997. (Coleção educação).

SILVA, Erivanildo Lopes da. Contextualização no Ensino de Química: Ideias e Proposições de um Grupo de Professores. Dissertação de Mestrado, Universidade de São Paulo, Programa de Pós-graduação Interunidades em Ensino de Ciências, São Paulo, 2007. 
SILVA, E. L.; MARCONDES, M. E. R. Visões de Contextualização de Professores de Química na Elaboração de seus próprios Materiais Didáticos. Ensaio - Pesquisa em Educação em Ciências, Belo Horizonte, 12(1), 2010, p. 101-108.

TENREIRO-VIEIRA, C; VIEIRA, R. M. Construção de práticas didático-pedagógicas com orientação CTS: Impacto de um programa de formação continuada de professores de ciências do ensino básico. Ciência \& Educação, 11(2), 2005, p. 191-211.

TRIVELATO, Silvia Luzia Frateschi. A formação de professores e o enfoque CTS. Pensamiento Educativo, v. 24, 1999, p. 201-234.

VILCHES, A.; SOLBES, J.; GIL, D. El enfoque CTS y la formación del professorado. In: MEMBIELA, Pedro (ed). Enseñanza de las Ciencias desde la Perspectiva Ciencia-Tecnología-Sociedad. Madrid: Narcea, 2001, p. 163-175.
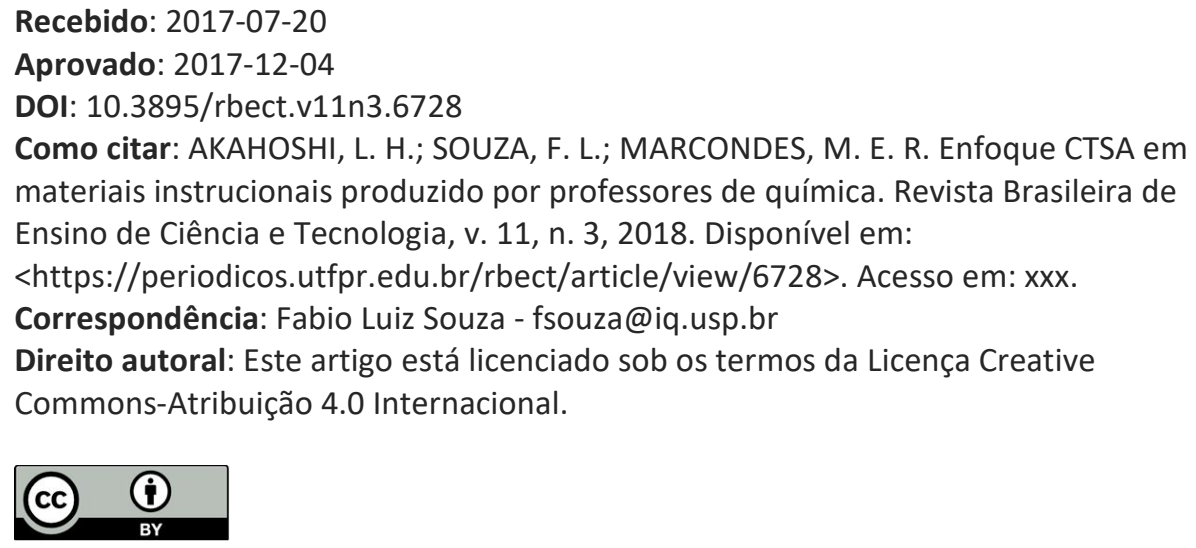